\title{
Reference guide for management of adult immune thrombocytopenia in Japan: 2019 Revision
}

\author{
Hirokazu Kashiwagi ${ }^{1}$ Masataka Kuwana ${ }^{2} \cdot$ Takaaki Hato $^{3} \cdot$ Toshiro Takafuta $^{4} \cdot$ Kingo Fujimura $^{5} \cdot$ Yoshiyuki Kurata $^{6}$. \\ Mitsuru Murata ${ }^{7}$. Yoshiaki Tomiyama, ${ }^{1,8}$. Committee for the Revision of "Reference Guide for Management of \\ adult ITP" Blood Coagulation Abnormalities Research Team, Research on Rare and Intractable Disease supported \\ by Health, Labour and Welfare Science Research Grants
}

Received: 27 September 2019 / Revised: 28 November 2019 / Accepted: 2 December 2019 / Published online: 2 January 2020

(c) Japanese Society of Hematology 2020

Keywords ITP · Thrombopoietin-receptor agonists · Rituximab $\cdot$ Splenectomy

\section{Introduction: aim of revision for the reference guide for management of adult immune thrombocytopenia (ITP)}

In 2012, ITP group of Blood Coagulation Abnormalities Research Team with funding from the Ministry of Health, Labour and Welfare Research Grant for Overcoming Intractable Diseases in Japan published a reference guide for management of adult immune thrombocytopenia (ITP) [1]. The reference guide was based on the existing global standards on ITP treatment, as well as research outcomes and expert opinions, and reflected the experience in Japan at that time.

The Japanese version of this reference guide was published in Jpn J Clin Hematol (Rinsho Ketsueki) 2019 60:877-896.

Yoshiaki Tomiyama

yoshi@hp-blood.med.osaka-u.ac.jp

1 Department of Hematology and Oncology, Osaka University Graduate School of Medicine, Suita, Japan

2 Department of Allergy and Rheumatology, Nippon Medical School Graduate School of Medicine, Tokyo, Japan

3 Division of Transfusion Medicine and Cell Therapy, Ehime University Hospital, Matsuyama, Japan

4 Department of Internal Medicine, Hiroshima City Funairi Citizens Hospital, Hiroshima, Japan

5 Department of Nursing Science, Yasuda Women's University, Hiroshima, Japan

6 Shitennoji Hidenin, Osaka, Japan

7 Department of Laboratory Medicine, Keio University School of Medicine, Tokyo, Japan

8 Department of Blood Transfusion, Osaka University Hospital, 2-15 Yamadaoka, Suita, Osaka 565-0871, Japan
A feature of the reference guide was clarification of $H$. pylori-associated ITP, which is a unique characteristic of ITP cases in Japan. The reference guide also clarified the criteria for starting treatment for ITP, as well as the treatment target and presented a flowchart of treatment, with corticosteroids as first-line treatment, splenectomy as second-line and other treatments as third-line, together with the respective recommendation levels. The basic concepts of management of adult ITP have not changed significantly since that time, and the 2012 reference guide remains adequately effective. However, in the reference guide, thrombopoietin receptor agonists (TPO-RAs) were positioned as third-line treatment, as these products had only recently been approved in Japan. Since then, we have accumulated experience in the use of these drugs, and their long-term efficacy and safety continue to become clear. Furthermore, in 2017, the indications for rituximab, which has been positioned as second-line treatment in Europe and the US, were extended to adult ITP in Japan. Conversely, the number of patients undergoing splenectomy is declining, and there is an increasingly large divergence between decisions made in clinical practice and the reference guide regarding the selection of second-line treatment for patients resistant to corticosteroids. There is also an accumulation of new evidence on ITP treatment, including administration methods for corticosteroids used as first-line treatment, namely high-dose dexamethasone (HD-DEX).

For these reasons, this study group decided to examine the latest reports on adult ITP treatment and present a revised version of the reference guide for the management of adult ITP in Japan. The most significant revision is the new recommendation of TPO-RAs, rituximab,b and splenectomy as second-line treatment, in addition to recommending that 
each treatment is selected on a case-by-case basis, in line with the patient's conditions and lifestyle. These revisions were drafted and discussed by the "Reference Guide for management of adult ITP" preparatory committee, and were created based on the opinions of the researchers and research collaborators on Blood Coagulation Abnormalities Research Team, Research on Rare and Intractable Disease. The main aim of this reference guide is for it to be effectively used in clinical practice, so we also created some practical questions together with recommendation based on literature searches and opinions of the committee. The recommendation levels for each treatment were determined using the GRADE system (Grading of Recommendations, Assessment, Development and Evaluation), as used in the previous reference guide (Table 1) [2]. Please refer to previously published our Consensus Report in the case of management of ITP with pregnancy [3]. We hope that this 2019 revised reference guide will be utilized effectively by physicians who manage ITP patients every day.

\section{Overview of adult ITP}

\section{ITP epidemiology, pathology and diagnosis}

\section{Epidemiology and classification}

Primary immune thrombocytopenia (ITP) is an acquired disease that causes thrombocytopenia through an immunological mechanism $[4,5]$. Based on the number of designated intractable disease medical care certificates issued, approximately 25,000 people are affected by this condition in Japan. The number of new cases each year is estimated to be 2.16 people per 100,000 , and the disease commonly occurs in children aged 6 years or younger, women aged 20-34, and the elderly [6]. Primary ITP is classified as newly diagnosed ITP (within 3 months after diagnosis), persistent
ITP (3-12 months) and chronic ITP (12 months or longer) based on the onset timing [5].

\section{Pathology}

The pathological mechanism of ITP is thrombocytopenia caused by accelerated destruction of platelets opsonized by anti-platelet autoantibodies that mainly target platelet membrane glycoproteins [GPIIb/IIIa(CD41/CD61), GPIb/ IX(CD42), etc.] by reticuloendothelial systems in the spleen and other organs. The anti-platelet autoantibodies also induce maturation failure and apoptosis of megakaryocytes, leading to impairment of platelet production. In addition to anti-platelet autoantibodies, immune complexes, complement and cytotoxic $\mathrm{T}$ cells may also play a role in thrombocytopenia [4, 7-11]. Thus, ITP is regarded as a syndrome that involves various immunological abnormalities, and ITP treatment mainly aims to (i) inhibit production of anti-platelet autoantibodies, (ii) inhibit platelet destruction and phagocytosis, and (iii) recover platelet production. However, at present, the inability to accurately ascertain the mechanism of thrombocytopenia of individual patients is an impediment for treatment selection.

\section{Diagnosis}

No disease-specific tests for ITP have been established, so ITP is diagnosed basically by exclusion. That is, ITP is diagnosed if a patient has thrombocytopenia $(<100,000 /$ $\mu \mathrm{L}$ ), but erythrocytes (excluding anemia caused by bleeding or chronic iron deficiency) and leukocytes are normal, and other possible diseases that cause thrombocytopenia are excluded. Clinical findings and tests that may help for diagnosis are described below.

Medical interview and examination findings The medical interview should confirm the clinical course of thrombocytopenia and bleeding symptoms, whether the patient
Table 1 Levels of recommendations based on the definition of the GRADE system [2] \begin{tabular}{l}
\hline Strength of the recommendation \\
\hline 1. Strong \\
A high degree confidence that the desirable outcomes of an intervention exceed the undesirable effects \\
(or vice versa) in most patient populations \\
2. Weak \\
A lower degree confidence that the desirable outcomes outweigh undesirable outcomes (or vice versa) \\
Quality of supporting evidence \\
A. Evidence established from multiple RCTs or very strong evidence from observational studies \\
B. Limited Evidence from RCTs or strong evidence from observational studies \\
C. Evidence from RCTs with serious flaws or weak or indirect evidence from observational studies
\end{tabular}

GRADE Grading of Recommendations Assessment, Development and Evaluation

$R C T$ randomized controlled trial 
had an antecedent infection, the status of complications and concomitant medication, and family history. The medical interview should also take note of the presence/absence of bleeding symptoms and the characteristics of these symptoms. The purpura seen in ITP often ranges from petechiae to ecchymosis. Mucosal bleeding (epistaxis, gastrointestinal bleeding, hematuria, etc.) is often seen in serious cases of thrombocytopenia, where the platelet count has fallen to $\leq 10,000 / \mu \mathrm{L}$, and fatal cerebral hemorrhage occurs in around $1 \%$ of adult cases and around $0.4 \%$ of pediatric cases [12]. Deep bleeding, such as intraarticular bleeding and intramuscular bleeding, is rare. Many adult cases with chronic ITP lack bleeding symptoms.

\section{Laboratory tests}

i. Peripheral blood: it is important to carefully monitor peripheral blood smears together with the blood count. Platelet aggregates are seen in pseudothrombocytopenia. The size of the platelets often increases in ITP, but when there is a notable increase in giant platelets, the condition may be caused by Bernard-Soulier syndrome or MYH9-related disorders (May-Hegglin anomaly, etc.). The presence of schistocytes is suggestive of thrombotic thrombocytopenic purpura (TTP) or disseminated intravascular coagulation (DIC).

ii. Bone marrow examination: bone marrow examination is important to rule out leukemia and myelodysplastic syndrome (MDS), as well as thrombocytopenia caused by bone marrow hypoplasia, but there are no findings specific to ITP and it is not considered to be an essential for the diagnosis of ITP [13]. However, the examination of bone marrow should be performed to rule out other diseases when abnormalities are found in erythrocytes or leukocytes, or in patients resistant to ITP treatments.

iii. Percentage of reticulated platelets $(\mathrm{RP} \%)$ and plasma (serum) thrombopoietin (TPO) concentration: The platelet lifespan is shortened in ITP, so the RP\%, which shows the percentage of immature young platelets, is often high in ITP patients [14, 15]. The percentage of immature platelet fraction (IPF\%), measured with an automated blood cell counter, is equally useful as RP\% [16]. The plasma (serum) TPO concentration stays within the normal range to slightly elevated in ITP, but it is markedly high in thrombocytopenia caused by bone marrow hypoplasia. These tests may be useful for differentiating ITP from hypoplastic thrombocytopenia such as aplastic anemia [14, $15,17]$, but they are not covered by Japanese health insurance. iv. Autoantibodies against GPIIb/IIIa (or GPIb/IX): Currently, PAIgG (platelet-associated $\mathrm{IgG}$ ) test is covered by Japanese health insurance, but it has low specificity for ITP and the diagnostic value is poor [18]. On the other hand, detection of autoantibodies against GPIIb/ IIIa or GPIb/IX, or detection of GPIIb/IIIa-reactive B cells (by the ELISPOT method) may be useful for ITP diagnosis [17], but only a limited number of laboratories can perform these tests, and they are not covered by Japanese health insurance.

\section{Therapeutic target and determining therapeutic effect [1]}

The therapeutic target for chronic ITP is not to return the platelet count to normal, but rather to maintain a platelet count sufficient to prevent serious bleeding (usually $\geq 30,000 / \mu \mathrm{L}$ ). The adverse reactions associated with long-term excessive administration of drugs to normalize the platelet count often reduce the patient's quality of life (QOL), so it should be avoided.

Therapeutic effect is determined in accordance with the following criteria. It is essential that platelet count measurements, acquired using two or more measurements taken at least 1 week apart, satisfy the criteria.

Complete response (CR): platelet count is $\geq 100,000 / \mu \mathrm{L}$ with no bleeding symptoms.

Partial response (PR): platelet count is $\geq 30,000 / \mu \mathrm{L}$ and two or more times higher than the pre-treatment level, with no bleeding symptoms.

No response (NR): applicable to at least one of the following: the platelet count is $<30,000 / \mu \mathrm{L}$, or less than two or more times higher than the pre-treatment level, with bleeding symptoms.

\section{Treatment flow (Fig. 1)}

When diagnosed with ITP, it must first be determined whether the patient has a Helicobacter pylori (H. pylori) infection. Eradication therapy in patients with $H$. pylori infection results in an increased platelet count in 50-70\% of patients for whom eradication is successful. However, emergency treatment is prioritized in patients with severe bleeding symptoms, and in patients who are at risk of fatal bleeding.

In patients who test negative for $H$. pylori infection or whose platelet count does not increase with eradication therapy, indication for treatment is decided based on the bleeding symptoms and platelet count. When the platelet 


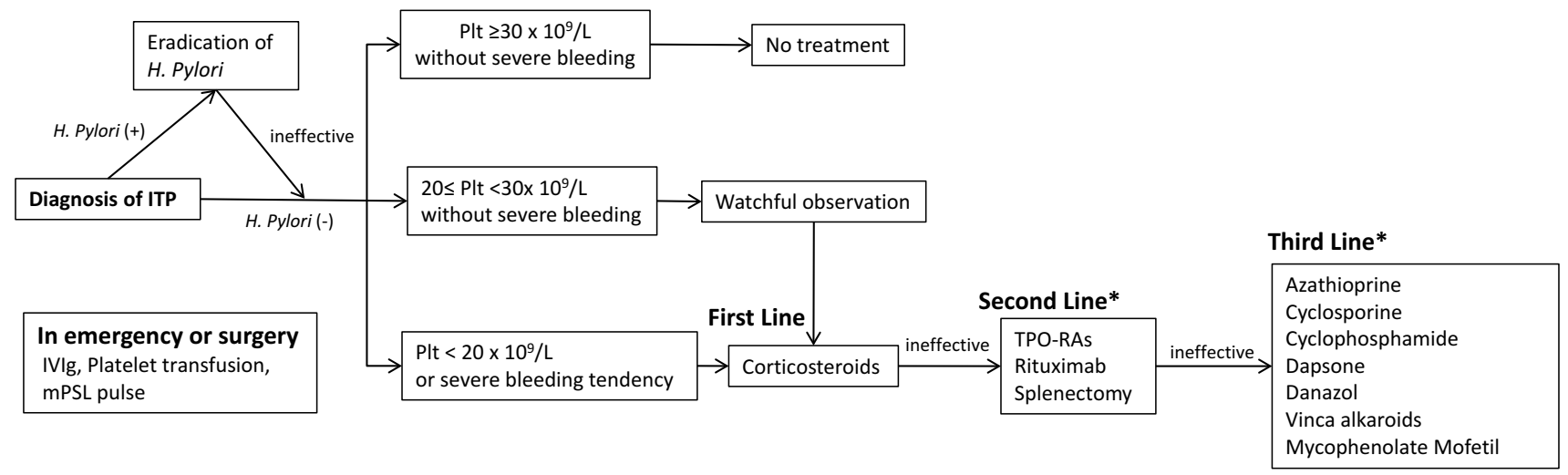

Fig. 1 Flowchart of adult ITP treatment. *Arbitrary order

count is $\geq 30,000 / \mu \mathrm{L}$ and the patient has no or mild bleeding symptoms, their condition could be monitored without treatment. In patients with a platelet count of $\geq 20,000 / \mu \mathrm{L}$ and $<30,000 / \mu \mathrm{L}$ with no or mild bleeding symptoms, it is recommended that their condition is carefully monitored, and indications for treatment should be determined considering the individual patient's bleeding risk, including their age and comorbidities. In patients with a platelet count of $<20,000 / \mu \mathrm{L}$ or with serious bleeding symptoms (cerebral hemorrhage, melena, hematemesis, hematuria, excessive genital bleeding, severe epistaxis or oral hemorrhage, injury where hemostasis is difficult, etc.), multiple purpura, petechiae or mucosal bleeding, immediate start of treatment is recommended. Aggressive therapy is particularly important in severe cases when the platelet count is $<10,000 / \mu \mathrm{L}$ and when there is gastrointestinal bleeding or intracranial bleeding.

The first-line treatment is corticosteroids. Patients who do not achieve the therapeutic target with corticosteroids or require long-term administration of high-dose corticosteroids, or patients unable to tolerate corticosteroids due to complications or adverse drug reactions, are transitioned to second-line treatment. TPO-RAs, rituximab and splenectomy are recommended as second-line treatments. Selection of the second-line treatment should be based on consideration of the advantages and disadvantages of each treatment, and to suit the situation of each individual patient. Thirdline treatment should be considered for refractory ITP cases where the second-line treatment is ineffective or is difficult to implement due to complications or other factors, after fully considering the necessity of the treatment.

High-dose intravenous immunoglobulin, methylprednisolone pulse therapy, or platelet transfusion should be considered for patients with severe bleeding symptoms, marked thrombocytopenia or who urgently require an increase in their platelet count because of surgery or for some other reason.

\section{Details of treatments}

\section{H. pylori eradication therapy (recommendation level: 1B)}

Since the report of Gasbarrini et al. [19] which demonstrated that platelet count increases after eradication of $H$. pylori in adult ITP patients, the effect of this treatment for ITP has been demonstrated in a large number of retrospective and prospective observational studies. Meta-analysis has also been implemented, and it has been proven that the platelet count increases with successful eradication in adult ITP cases infected with $H$. pylori [20-22]. Studies conducted in Japan have reported that platelet response is obtained in about $50-70 \%$ of patients in cases treated with eradication therapy. In cases where the platelet count recovers to $\geq 100,000 / \mu \mathrm{L}$, few recurrences occur in the long-term follow-up, not only in mild cases but also in refractory cases not responsive to splenectomy [23]. Patients responsive to H. pylori eradication therapy have reduced production of anti-platelet antibodies, suggesting that their autoimmune pathophysiology is suppressed by eradication [24]. Therefore, within ITP, there is a unique subtype in which $H$. pylori infection is significantly involved in the pathology. This type is called H. pylori-associated ITP and is classified as secondary ITP in Europe and the US. H. pylori eradication therapy is more effective than corticosteroids, at least in Japan, and has fewer adverse reactions, so the 2012 reference guide recommends testing for $H$. pylori infection in all patients diagnosed with ITP and, if the patient is confirmed to be a carrier, that eradication therapy should be prioritized irrespective of the platelet count or bleeding symptoms [1]. In Japan, ITP was added to the indications of $H$. pylori eradication therapy in 2010.

There are geographic differences in the efficacy rate of H. pylori eradication therapy for ITP, with an efficacy rate 
of $50 \%$ or more in East Asia, including Japan, Central and South America and Italy, but an efficacy rate of less than $10 \%$ in reports from European countries other than Italy and from North America [21]. The efficacy rate is also low in children, and the treatment is normally ineffective in secondary ITP with underlying diseases, such as systemic lupus erythematosus [25].

\section{Indication}

This treatment is indicated for all cases in which the patient is infected with H. pylori.

At first, all patients, including in cases where response was achieved with emergency treatment, should receive evaluation of $H$. pylori infection. Preferential tests are (i) a urea breath test, (ii) a $H$. pylori stool antigen test, and (iii) a serum or urine anti-H. pylori $\operatorname{IgG}$ antibody test. Invasive methods that use an endoscope (histological examination, rapid urease test, cultivation) should be avoided.

The test may produce a false-negative result if the patient is taking antibiotics, proton pump inhibitors (PPI), or potassium-competitive acid blockers (P-CAB), or if the patient is being treated with immunosuppressant therapy, so it is recommended that two or more tests be conducted.

\section{Treatment regimen}

Treatment should be in accordance with the 2016 revision of the Guidelines for Diagnosis and Treatment of H. pylori infection issued by the Japanese Society for Helicobacter Research [26]. Primary eradication involves a three-drug combination of PPI or P-CAB with clarithromycin and amoxicillin twice a day (after breakfast and dinner), taken together for 7 days. $\mathrm{P}-\mathrm{CAB}$, vonoprazan, containing regimen has a higher eradication success rate than the conventional regimen using PPI [27].

- PPI or P-CAB (omeprazole, lansoprazole, rabeprazole, esomeprazole, or vonoprazan), twice daily for 7 days

- Amoxicillin $1500 \mathrm{mg}$, twice daily for 7 days

- Clarithromycin $400 \mathrm{mg}$ or $800 \mathrm{mg}$, twice daily for 7 days

- From 4 to 8 weeks after completing eradication regimen, implement the urea breath test or $H$. pylori stool antigen test to determine if eradication was successful. It is necessary to wait at least 6 months before conducting the serum anti-H. pylori $\mathrm{IgG}$ antibody test.

- Metronidazole can be used instead of clarithromycin for secondary eradication, but the eradication success rate is lower than primary eradication, so it is preferable for these cases to be treated by a gastroenterologist or a doctor accredited by the Japanese Society for Helicobacter Research.
- Convenient 3-drug pack preparations are widely used (Rabecure, Lansap, Vonosap, Rabefine, Lampion, Vonopion).

- Cases with a temporary reduction in platelet counts and worsening of bleeding symptoms after eradication therapy have been reported [28], so it is recommended that eradication therapy be implemented after increasing the platelet count with corticosteroids or high-dose immunoglobulin in patients with a platelet count of $\leq 10,000 / \mu \mathrm{L}$ or clinically significant bleeding symptoms.

\section{Efficacy}

A national survey conducted in Japan found that platelet counts increased by $63 \%$ of patients with successful eradication [28]. A systematic review of 1555 cases, including data from Europe and the US, where the efficacy of $H$. pylori eradication therapy is low, reported that the platelet count increased to $\geq 100,000 / \mu \mathrm{L}$ in $42.7 \%$ of patients, while the platelet count increased to $\geq 30,000 / \mu \mathrm{L}$ and double the previous level in $50.3 \%$ of patients [21].

\section{Safety}

Adverse drug reactions to eradication therapy that occurred in $\geq 10 \%$ of cases include gastrointestinal symptoms, such as soft stool, diarrhea and abdominal distension, as well as taste disorders, but the reactions were mild and disappeared after completion of treatment. Rashes are seen in $\geq 5 \%$ of cases, and some patients have an allergic reaction not only to the drugs used for treatment but also to extracellular vesicles released from dead H. pylori [29]. Rarely this treatment causes toxic epidermal necrosis and Stevens-Johnson syndrome. It can also cause temporary thrombocytopenia, so treatment should be avoided in patients with significant bleeding symptoms. It is preferable to continue taking the drugs for 1 week even if adverse drug reactions develop, provided the reactions are mild, to increase the eradication success rate and prevent the occurrence of antibiotic-resistant bacteria.

\section{First-line treatment: corticosteroid therapy (recommendation level: 2B)}

Corticosteroids mainly demonstrate an effect on ITP by (i) inhibiting destruction of antibody-bound platelets by the reticuloendothelial system, (ii) inhibiting production of anti-platelet autoantibodies, and (iii) inhibiting destruction of megakaryocytes by macrophages in the reticuloendothelial system, such as spleen, or cytotoxic $\mathrm{T}$ cells in the bone marrow $[4,7,11$, 30, 31]. Corticosteroids have been key drugs for ITP treatment since the 1950s. In 1994, George et al. reviewed 12 reports on 
adult ITP treatment and found that 1447 of 1761 ITP cases were treated with corticosteroids, of which 370 cases (approximately 25\%) achieved a complete response [7]. When using this treatment, it is essential to be fully cognizant of the adverse drug reactions associated with corticosteroid treatment.

\section{Indication}

Corticosteroids are selected as first-line treatment for patients who test negative for $H$. pylori at initial ITP diagnosis or patients who test positive but are unresponsive to eradication, who have a platelet count of $<20,000 / \mu \mathrm{L}$ or critical bleeding symptoms, multiple purpura, petechiae and/or mucosal bleeding. It is important to consider the risk factors for bleeding, including the age of the individual patient and comorbidities, to determine indications for treatment in patients with a platelet count of $20,000-30,000 / \mu \mathrm{L}$. In patients with underlying diseases (hypertension, diabetes, active infections, chronic infections, impaired immune status,osteoporosis, dys lipidemia,peptic ulcer, etc.) with a high probability of problematic adverse drug reactions associated with corticosteroid treatment, it is recommended that corticosteroids be started while controlling complications.

\section{Treatment regimen}

As initial treatment, prednisolone (PSL) $0.5-1 \mathrm{mg} / \mathrm{kg} / \mathrm{day}$ is given orally for 2-4 weeks. Then, irrespective of whether the platelet count has increased, the dose is tapered over $8-12$ weeks until it is reduced to $10 \mathrm{mg} /$ day or less $[1,2,7$, $13,32,33]$. Consider starting the initial corticosteroid dose at $0.5 \mathrm{mg} / \mathrm{kg} /$ day for patients with the aforementioned underlying diseases and elderly patients aged 60 years and older.

Reduce the corticosteroid dose, and if possible, stop administration in patients who achieve CR with corticosteroid therapy. For patients who do not reach $\mathrm{CR}$, reduce the corticosteroid dose in which the platelet count can be maintained at $\geq 30,000 / \mu \mathrm{L}$, a level which does not affect survival prognosis. Namely, monitor their progress at a maintenance dose of PSL $\leq 10 \mathrm{mg} /$ day and aim to maintain good QOL, including reducing drug-induced adverse drug reactions. If these therapeutic effects are not seen, the patient's condition is deteriorating, or this treatment cannot be used because of adverse drug reactions and/or complications, then select second-line treatment to avoid bleeding risks and improve QOL.

\section{Efficacy}

The platelet count increases to $\geq 30,000 / \mu \mathrm{L}$ in approximately $80 \%$ of patients, and the platelet count increases to $\geq 100,000 / \mu \mathrm{L}$ in approximately $50 \%$ or more of those patients. However, the platelet count declines as the corticosteroid dose is tapered, and reports indicate that only $10-25 \%$ of patients are able to cease corticosteroids with remission [7, 34].

\section{Safety}

There are various adverse drug reactions associated with corticosteroids, and the incidence of adverse drug reactions is also affected by individual differences, including the patient's age, and whether they have an underlying disease, so it is often necessary to adjust the dose or stop administration.

Immunodeficiency Patients' immune status becomes impaired and they become immunocompromised, particularly with long-term administration of corticosteroids. Particular attention should be paid to cases of opportunistic infection, such as fungal infections, including pneumocystis pneumonia, and herpes virus infections, etc. Hepatitis B virus (HBV) can be reactivated when using a moderate or higher dose of corticosteroids [35]. Referencing the "Guideline for Treating Hepatitis B caused by Immunosuppression or Chemotherapy" issued by the Japan Society of Hepatology, HB antigens, and HBc and HBs antibodies should be measured before starting corticosteroids. If the patient tests positive for any of these, it is essential to determine whether the patient currently has a HBV infection or has a history of infection by measuring HBV-DNA.

Diabetes mellitus It is important that patients who have been diagnosed with diabetes continue to strictly control their condition. Elevated blood sugar can become problematic after starting corticosteroids in patients with borderline diabetes, obese patients, and elderly patients; thus, caution is needed. Elevated blood sugar can also become problematic even in patients without a relevant medical history or underlying disease, so the blood sugar levels of all patients should be regularly monitored after starting treatment.

Peptic ulcer Corticosteroids can induce the onset of peptic ulcers such as gastric ulcers. A hemorrhagic ulcer occurring while the platelet count is notably reduced can cause anemia and can also trigger critical conditions such as hypotension, so corticosteroids should be administered with PPI as appropriate. It is recommended to proactively perform endoscopy for patients who may have a peptic ulcer.

Other It is vital to take sufficient precautions for general adverse drug reactions to corticosteroids, including hypertension, dyslipidemia, and osteoporosis. Refer to the guidelines for the respective disease regarding the treatment of each disease. 
Question. Is high-dose dexamethasone (HDDEX) more effective than conventional PSL therapy?

Answer. There is little evidence that HDDEX is more effective than conventional PSL, so it is recommended to use conventional PSL therapy as first-line treatment. However, HD-DEX may be selected for young patients with severe thrombocytopenia who require a prompt increase in their platelet count.

Commentary】

Since Andersen et al. reported the therapeutic effect of HD-DEX (dexamethasone $40 \mathrm{mg} /$ body $\times 4$ days) on refractory cases in 1994, there have been a number of reports investigating its efficacy for refractory cases, but the efficacy differs depending on the report, and no fixed opinion has been established [36-44]. The efficacy of HD-DEX for newly-diagnosed ITP cases has been reported since a report by Cheng et al. in 2003 [45-50]. In 2016, Mithoowani et al. reported the results of a meta-analysis on treatment using HD-DEX and PSL [51]. According to that meta-analysis, the overall platelet count response in five randomized control trials (RCTs) $(n=533)$ was significantly more effective in the HD-DEX group than in the PSL group after 14 days (HD-DEX: 79\% vs PSL: 59\%), but there was no significant difference between the two groups after 6 months (54\% vs $43 \%)$. These findings suggest that HD-DEX may be more effective than PSL at promoting early recovery of the platelet count, but there is little evidence that its efficacy exceeds that of PSL in the long term. Therefore, at the current time, conventional PSL is recommended as first-line therapy for newly-diagnosed ITP. The results of the metaanalysis found that HD-DEX had a lower incidence of adverse drug reactions, but it can induce notable immunodeficiency in elderly patients and other adverse effects, so careful administration is essential.

Note that HD-DEX is not covered by Japanese health insurance.

\section{Second-line treatment}

TPO-RAs, rituximab, and splenectomy are recommended as second-line treatment. It has been 7 years since the oral TPO-RA agent eltrombopag and the subcutaneous injection romiplostim received marketing authorization in Japan. The efficacy and safety of long-term use of both medications 
Table 2 Comparison of second-line treatments

\begin{tabular}{|c|c|c|}
\hline & Merit & Demerit \\
\hline \multirow[t]{8}{*}{ TPO-RAs } & & Need for long-term administration for most patients \\
\hline & & Fluctuations in platelet count in some patients \\
\hline & High response rate $(>80 \%)$ & Need for meal and drug restriction (eltrombopag) \\
\hline & Mild side effects & Need for attending hospital and subcutaneous injection once a week (romiplostim) \\
\hline & No immunosuppressive effects & Possibility of headache, liver dysfunction (eltrombopag), thrombosis and BM fibrosis \\
\hline & Possibility of long-term remission even after & No long-term safety data ( $>10$ years) \\
\hline & withdrawal in minor group (3-20\%) & Safety is not established in pregnant women \\
\hline & & Expensive \\
\hline \multirow[t]{4}{*}{ Rituximab } & Response rate is $50-60 \%$ & Low long-term response rate $(20-30 \%)$ \\
\hline & Completion of treatment in 4 weeks & Possibility of severe infusion reaction \\
\hline & Generally well tolerated & Possibility of immunological impairment (low response to vaccine, reactivation \\
\hline & Possibility of better response in young women & of HBV, PML (very rare) \\
\hline \multirow[t]{3}{*}{ Splenectomy } & $\begin{array}{l}\text { Good response rates }(>80 \%) \text { and high pos- } \\
\text { sibility of life-long cure }(60-70 \%)\end{array}$ & $\begin{array}{l}\text { Surgery-related complications (ileus, abdominal bleeding, portal vein thrombosis, } \\
\text { infection, etc.) }\end{array}$ \\
\hline & Achieve a response in a few days & Life-long small increased risk of serious infection \\
\hline & & Life-long small increased risk of venous thrombosis \\
\hline
\end{tabular}

have been reported $[52,53]$. The efficacy rate is high, but continuous treatment is required except a few cases, and caution is needed regarding adverse drug reactions, such as thrombosis. The efficacy of rituximab is inferior to splenectomy and TPO-RAs, but treatment is completed in a short timeframe, and the treatment enables early recovery of the platelet count and remission in the long term in certain cases. Splenectomy has the highest efficacy rate and can be expected to be curative in approximately two-thirds of cases. However, this procedure results in life-long reduced immunity against Streptococcus pneumoniae, Neisseria meningitidis and Haemophilus influenzae, and also increases the risk of thrombosis. No RCTs have directly compared these treatments. There are advantages and disadvantages to each treatment, which makes it impossible to uniformly determine the priorities of each treatment (Table 2). The condition and situation of each individual patient, including their complications, age and lifestyle, must be ascertained, and the treatment should be selected with consideration for the patient's own wishes.

\section{Indication}

Patients who are non-responsive to corticosteroid therapy or who are unable to take sufficient doses of corticosteroids due to complications (corticosteroid intolerance) are indicated for this treatment. Many patients who respond to corticosteroids have a reduction in their platelet count as the dose of the corticosteroids is reduced, and quite often these cases have been treated by increasing the corticosteroid dose again. However, long-term administration of corticosteroids increases the risk of adverse drug reactions, so now that multiple effective therapeutic options are available, early transition to second-line treatment should be considered. However, it is preferable to consider splenectomy 6-12 months after onset.

\section{Thrombopoietin receptor agonists (TPO-RAs) (recommendation level: 1A)}

TPO-RAs are drugs that bind to the TPO receptors (c-Mpl) expressed on megakaryocytes and hematopoietic stem cells, which enhance platelet production by promoting differentiation and maturation of megakaryocytes. The platelet count starts to increase about 5-7 days after starting administration and peaks at day 12-16. Continuous use can maintain the effect of increased platelet count. The currently available drugs are romiplostim, eltrombopag and lusutrombopag, but only romiplostim and eltrombopag are approved for the treatment of ITP in Japan.

\section{Treatment regimen}

- Romiplostim: $1-10 \mu \mathrm{g} / \mathrm{kg}$, once a week, via subcutaneous injection, starting from $1 \mu \mathrm{g} / \mathrm{kg}$ at the initial dose, with the dose increased or reduced as appropriate depending on platelet count and symptoms.

- Eltrombopag: $12.5-50 \mathrm{mg} / \mathrm{day}$, once a day, taken on an empty stomach $2 \mathrm{~h}$ before or after meals, starting from a $12.5 \mathrm{mg}$ oral dose, with the dose increasing every 2 weeks up to $50 \mathrm{mg}$ until sufficient effect is achieved. 
Efficacy A number of RCTs have been conducted, including studies conducted in Japan, for both romiplostim and eltrombopag on corticosteroid-resistant refractory ITP cases [53-63]. Meta-analyses that compiled the results of these RCTs found that both drugs significantly improved overall and continuous platelet response compared to the control group $[64,65]$. A comparison of a group treated with splenectomy and a group not treated with splenectomy found that both drugs had slightly reduced reactivity in the splenectomy group, but they were still effective in $\geq 80 \%$ of cases (romiplostim: splenectomy group $=82 \%$, non-splenectomy group $=91 \%$, eltrombopag: splenectomy group $=80 \%$, nonsplenectomy group $=89.3 \%)[53,66]$. The incidence of all bleeding events and critical bleeding events, and events that required emergency treatment were significantly lower in the TPO-RAs group, and there were also significantly more patients in the TPO-RAs group who were able to reduce the dose or stop concomitant medication altogether (mainly corticosteroids) $[64,65]$. These results were also confirmed in large-scale observational studies in Europe [67, 68].

It was also reported that long-term remission was achieved even after stopping TPO-RAs for both romiplostim and eltrombopag in around 3-4\% of patients in the clinical trials and around $10-20 \%$ of patients in subsequent retrospective reports [69-72]. The mechanism of inducing remission with TPO-RAs is unknown, but possible mechanisms are as follows: (i) immunotolerance to platelet autoantigens may have been induced as a result of the increased platelet number by TPO-RAs or (ii) TPO-RAs may have improved the function of regulatory T cells (CD4+, CD25hi) [73, 74]. Thus, when the platelet count is maintained at $\geq 100,000 / \mu \mathrm{L}$, reduction of the TPO-RAs dose may be considered, while monitoring fluctuations in platelet count.

Safety There are concerns about adverse drug reactions such as those listed below, given the pharmacological action of TPO-RAs.

Thrombosis TPO may lead to pre-activated state of platelets [75], so an increase in thrombosis is the most concerning the potential adverse event. However, large-scale cohort studies have shown that ITP itself increases arterial and venous thrombosis [76-78], which makes it difficult to determine the effect of the TPO-RA itself. There was no significant increase in the incidence of thrombosis in the clinical trials on romiplostim and eltrombopag $[63,79]$. However, nearly all cases of thrombosis in users of eltrombopag, both arterial and venous thrombosis, occur within 1 year after starting treatment, and reports indicate that there are almost no new cases from 4 years post-treatment onwards [53], thus, it is essential to be mindful of the onset of thrombosis, particularly in the early stages of TPO-RAs treatment. Use of TPO-RAs should be carefully considered in patients with congenital or acquired thrombophilia, namely, patients with a history of thrombosis, hypertension, smoking, obesity, diabetes, dyslipidemia, antiphospholipid antibodies, and in patients with cancer.

Myelofibrosis A report on long-term administration of eltrombopag found that $11 / 356(6.6 \%)$ patients developed myelofibrosis requiring clinical attention, but there were no symptoms suggestive of an abnormal blood count or morphology, or bone marrow failure [53]. It was also reported that increase of reticuline fibers improved on stopping of TPORAs treatment [80]. On the other hand, another report from a single institution found that clinically significant fibrosis (MF-2 or higher) may occur in one-fifth of patients administered TPO-RAs long term [81]. While using TPO-RAs, it is essential to pay attention to peripheral blood findings, including smears, and if findings suggestive of myelofibrosis are found, then a bone marrow biopsy should be performed in advance and discontinuation of TPO-RAs must be considered.

Increase in blast cells TPO receptors are expressed not only on megakaryocytes but on hematopoietic stem cells as well, so an increase in blast cells is a concern when using TPO-RAs in patients with leukemia. There have been no reports of acute leukemia in clinical trials on eltrombopag and romiplostim for ITP, and although malignant tumors, including lymphoma, have been reported, it is unlikely that these events were directly related to TPO-RAs [53]. Progression of acute myeloid leukemia (AML) was a concern in an interim analysis of a clinical trial investigating the effect of romiplostim on MDS [82], but the results of the subsequent final analysis demonstrated that use of romiplostim was unlikely to increase the incidence of AML [83]. However, since there is also a report suggesting a correlation between TPO-RAs use and leukemia [84], it is preferable to rule out the possibility of MDS with bone marrow examination before starting TPO-RAs.

Other An adverse drug reaction associated with eltrombopag that requires attention is liver dysfunction, and it has been seen in approximately $15 \%$ of treated cases [53, 85]. Cataracts were indicated in toxicity tests of eltrombopag using rodents [85]. This may reflect the effect of concomitant drugs, such as corticosteroids, but regular ophthalmological examinations are recommended.

There have been reports of anti-drug antibody production associated with romiplostim, but there have been no reports to date of production of antibodies that cross-react with endogenous TPO [85].

Question. Which should be prioritized,

eltrombopag or romiplostim?

Answer. There is no difference in efficacy or safety, so drug selection should be based on 


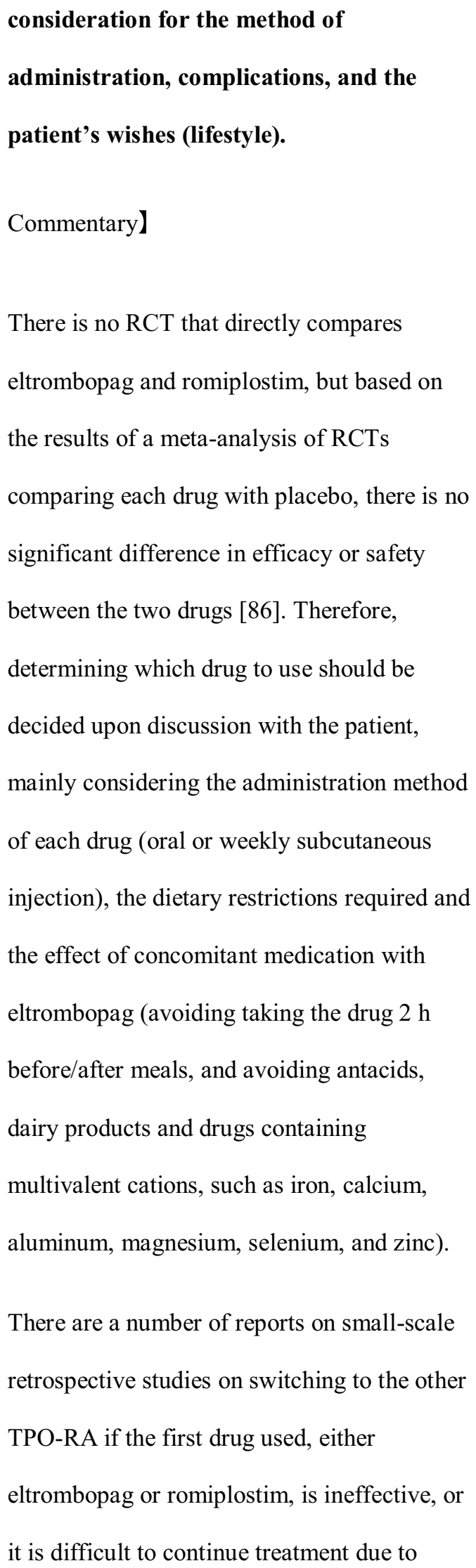

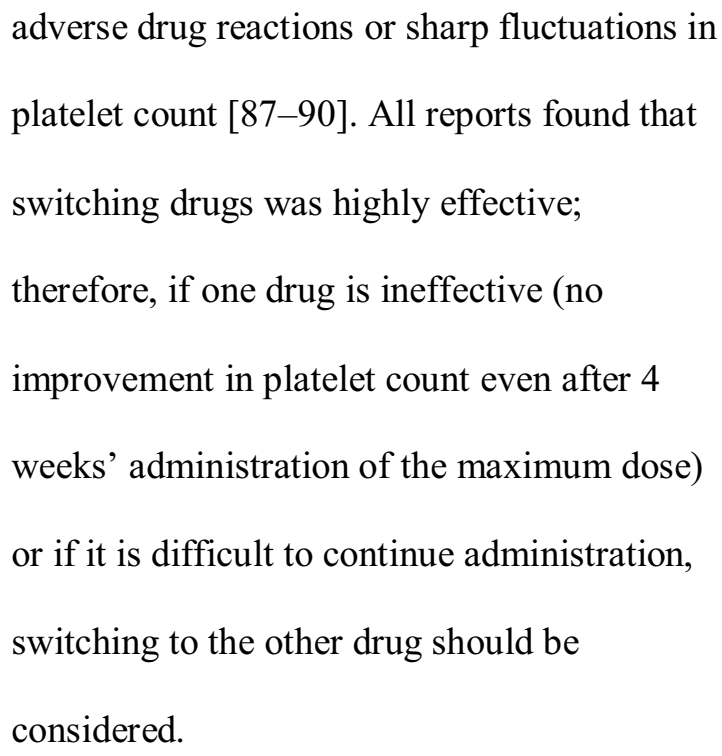

\section{Rituximab (recommendation level: 2B)}

Rituximab is a human-mouse chimeric monoclonal antibody that recognizes CD20 antigens expressed on B cells, and it works to reduce anti-platelet antibodies by reducing B cells. The indication of rituximab was expanded to include ITP in Japan in March 2017.

Treatment regimen Intravenous infusion of rituximab $375 \mathrm{mg} / \mathrm{m}^{2}$ once a week for 4 weeks.

Efficacy Multiple RCTs have been conducted on rituximab for ITP patients and a meta-analysis on those RCTs has also been reported [91]. In five RCTs on adult ITP patients [92-96] $46.8 \%$ of patients in the rituximab treatment group achieved a complete response with a platelet count of $\geq 100,000 / \mu \mathrm{L}$, while this figure was $32.5 \%$ in the standard treatment group, suggesting that the rituximab group was superior, with a relative risk of 1.42 (95\% CI: 1.13-1.77, $p=0.002$ ). However, the percentage of patients who had a partial response with a platelet count of $30,000-50,000 / \mu \mathrm{L}$ was $57.6 \%$ in the rituximab group and $46.7 \%$ in the standard treatment group, with a relative risk of 1.26 (95\% CI: $0.95-1.67, p=0.11$ ), indicating that there was no significant difference in the bleeding inhibition effect between the two groups. There was also no difference between the two groups in terms of onset of infection. In three of these five RCTs, rituximab was combined with dexamethasone and was compared with a dexamethasone monotherapy group, so the results reflect the additional effects of rituximab combined with dexamethasone $[92,93,95]$. In the remain- 
ing two RCTs, rituximab monotherapy was compared with saline infusion in a blinded manner, although both groups were permitted concomitant use of low-dose corticosteroids. These two studies address the clinical question as to whether rituximab is effective in corticosteroid-resistant or -dependent patients $[94,96]$. There was no significant difference in any of the aforementioned indicators, including complete response rate, in the two RCTs. However, the time to relapse was significantly longer in the rituximab group compared to the placebo group (36 weeks vs 7 weeks, $p=0.01$ ), so there are benefits for patients who respond to rituximab [96]. An investigator-initiated clinical trial in Japan found that 4 of 26 patients (14.5\%) administered rituximab had a complete response, and 30.8\% (95\% CI: $14.3-51.8 \%$ ) had a partial response with a platelet count of $\geq 50,000 / \mu 1$ [97]. This study was conducted in ITP patients resistant to other treatments and found that rituximab had a certain level of clinical efficacy.

An increase in the platelet count is seen approximately 1-3 months after starting administration of rituximab [98-100]. The median duration of the platelet response to rituximab is 1 year, and relapse occurs over time even if remission is achieved, Approximately $20-30 \%$ of patients maintain a platelet count of $\geq 50,000 / \mu \mathrm{L}$ over 5 or more years after rituximab administration [101-103]. Re-administration of rituximab after relapse produces a similar response as the initial administration in $75 \%$ of patients [104]. Some patients achieve remission again with rituximab after each subsequent relapse [105]. The long-term prognosis of the effect and safety in ITP patients repeatedly administered rituximab is unknown.

There are retrospective reports that rituximab is more effective in women, patients younger than 40 years of age, and patients treated within 1 year of ITP diagnosis [100, 102, $105,106]$. However, there are also reports indicating no correlation with these factors $[95,101,107]$ as well as a report stating that the treatment tends to be more effective in men [103], so these are not established predictors of the effects of rituximab. The relationship between the presence and/or elimination of autoantibodies against platelet glycoproteins and the response to rituximab has also been investigated, but at present there is no definitive opinion on this matter [108-110]. The effect of rituximab is unrelated to whether or not the patient has had a splenectomy $[107,111]$.
Safety Acute infusion reactions Generally, these reactions are observed between 0.5 and $2 \mathrm{~h}$ after starting administration, and often occur with the first administration. The symptoms include fever, chills, headache, rash, angioedema, and cough. Rarely it can cause anaphylactic-like symptoms, lung disorders (bronchospasm, infiltration of the lungs, acute respiratory distress syndrome) and cardiac disorders (myocardial infarction, ventricular fibrillation, cardiogenic shock). Administration of antihistamines, antipyretic analgesics or corticosteroid 30 min before administering rituximab and maintenance of a slow infusion rate at the start of administration are effective in mitigating these symptoms.

Reactivation of $H B V$ Administering rituximab to HBV carriers and HBV infected patients can reactivate HBV and increases the risk of de novo hepatitis. It is essential to follow the "Guideline for Treating Hepatitis B caused by Immunosuppression or Chemotherapy" published by The Japan Society of Hepatology when treating these patients.

Infection There are concerns of inducing a compromised state based on the mechanism of action of rituximab, but no difference in the incidence of infection between the rituximab group and the control group was detected in a metaanalysis of RCTs on ITP patients [9.2\% vs $5.2 \%$, relative risk 1.34 (95\% CI: $0.63-2.87, p=0.44)$ ] [91]. The results of a large-scale, long-term prospective study (median observation period was 2 years, ITP patients $n=248$ ) revealed that the infection incidence rate was 2.3/100 human-years, and three of 11 patients with infection died [105]. Only one case of opportunistic infection was observed, in the form of sinus aspergillosis. This treatment is also known to cause progressive multifocal leukoencephalopathy (PML) through reactivation of JC virus, and there have been two cases reported after rituximab was administered to ITP patients $[112,113]$.

Other Rituximab is known to cause neutropenia, and this has been observed in ITP patients following administration of rituximab [105, 107]. Peripheral B lymphocytes disappeared after rituximab administration, but plasma cells were not damaged, and there was no significant change in blood immunoglobulin levels in all three ITP clinical trials that measured immunoglobulin over time [96, 105, 107]. 
Question. What is the appropriate dose of

rituximab for ITP?

Answer. At the moment, the standard dose

of $375 \mathrm{mg} / \mathrm{m}^{2} /$ week $\times 4$ doses is

recommended.

Commentary】

The rituximab dose most commonly used in studies to date is the standard dose which is used to treat lymphoma, $375 \mathrm{mg} / \mathrm{m}^{2} /$ week $\times 4$ doses, while some studies have used a lowdose regimen of $100 \mathrm{mg} / \mathrm{m}^{2} /$ week $\times 4$ doses [114-116]. No RCTs have directly compared these two dose regimens. Although the lowdose regimen was effective in the two observational studies, it had a shorter duration of effect and a lower response rate than the standard-dose regimen $[115,116]$. There is a report that the incidence of adverse events is lower with the low-dose regimen [114], but overall the standard dose is recommended because it has virtually the same profile in the examination of a large number of cases [115, 116]. An RCT was conducted to examine other doses, comparing three groups:

$375 \mathrm{mg} / \mathrm{m}^{2} /$ week $\times 2,750 \mathrm{mg} / \mathrm{m}^{2} /$ week $\times 2$

treatment groups and the standard treatment group, but there was no difference in response rate [100]. There is also a report on a prospective observational study with $1000 \mathrm{mg} / 2$ weeks $\times 2$, but there was no difference to the standard dose [117].

\section{Splenectomy (recommendation level: 1B)}

In the pathogenesis of ITP, the spleen is the site where macrophages phagocytose platelets with anti-platelet autoantibodies, and also functions as the site of anti-platelet autoantibody production by B cells [118-120]. Therefore, particularly in refractory ITP cases, the platelet count is expected to recover with splenectomy, and often this procedure enables the patient to stop pharmacotherapy, including corticosteroids. However, there are cases of spontaneous remission in ITP and in some cases, it takes time for the therapeutic effect to manifest, so it is preferable to consider splenectomy 6-12 months after diagnosis at the earliest [1, $2,13,121]$.

A number of factors with potential predictive value have been investigated, but no factors that enable prediction of the effect of splenectomy are known. Therefore, when selecting the option of splenectomy, various factors must be carefully considered, including the risks associated with surgery caused by underlying diseases and other factors, and it is important to fully explain the related factors, including the necessity of splenectomy, preoperative approaches, the surgical procedure, prognosis, efficacy rate, duration of surgery, and postoperative complications, and to obtain informed consent.

In terms of splenectomy for elderly patients with ITP, reports have shown that while elderly patients have a higher risk of perioperative bleeding and efficacy is inferior than in younger patients, at least 50\% achieve long-term remission [122]. Considering that this procedure enables patients to 
stop pharmacotherapy such as corticosteroids, it can improve long-term QOL in elderly patients, thus splenectomy may also be considered for elderly patients.

Preoperative management and surgical procedure

(1) Preoperative management. It is preferable to maintain a platelet count of $\geq 50,000 / \mu \mathrm{L}$ when performing splenectomy. Implement methods to systematically increase the platelet count, such as high-dose intravenous immunoglobulin (IVIg), and platelet transfusion, based on consideration of the surgery date. Recently, there has been a report on a splenectomy implemented with the platelet count maintained with TPO-RAs, and the efficacy of this treatment was demonstrated, but caution is essential due to the increased risk of postoperative thrombosis [123].

(2) Surgical procedure. Laparoscopic splenectomy is recommended over open splenectomy (explained in the Question section). However, the decision about the procedure is left to the surgeon. Efforts should be made to remove the accessory spleen, which may cause recurrence.

Efficacy A platelet increase response is seen in $80 \%$ of cases, but relapse occurs in approximately $20 \%$ of cases, and a permanent effect is said to occur in approximately $60 \%$ of cases [124]. In a previous report by this research team, it was found that $56.1 \%$ of cases maintained remission at the final observation point, 5 or more years after splenectomy [125].

Safety General postoperative complications associated with the surgical procedure such as ileus due to gastrointestinal adhesions, and intraabdominal bleeding, can occur after splenectomy. Other complications that require attention include infection and thrombosis (portal vein thrombosis, etc.) [126].

Infection The natural IgM antibodies required to eliminate encapsulated bacteria such as $S$. pneumoniae, $N$. meningitidis and $H$. influenzae are produced by B cells in the spleen. Therefore, the ability to defend against these bacteria is impaired after splenectomy, and there is an increased risk of overwhelming post-splenectomy infection (OPSI); thus, it is essential to prevent infection with appropriate vaccinations [127]. Post-splenectomy infections can become more serious than normal infections, so early treatment is essential. When the infection is suspected due to fever or other symptoms, promptly administer penicillin-based or new quinolone-based antibiotics and carefully monitor the patient for signs of the infection worsening. Many patients who undergo splenectomy are refractory cases who have had long-term treatment with immunosuppressants such as corticosteroids, so it is vital to be aware that some patients may have immunodeficiency associated with their previous treatments.

Thrombosis There have been reports of patients who develop abdominal venous thromboembolism (AbVTE), including portal vein and splenic vein thrombosis, or other venous thromboembolisms (VTE), such as lower limb venous thromboembolism, after splenectomy. Boyle et al. collected data on 9976 ITP patients, including 1762 splenectomy cases, and investigated complications associated with splenectomy [128], and reported that the incidence of AbVTE in non-splenectomy cases was $1 \%$, while that figure increased to $1.6 \%$ soon after surgery, within less than 90 days, in splenectomy cases. There was no such increase from 90 days onwards, so the increase in AbVTE may be affected by the splenectomy procedure itself. In a number of reports on VTE, splenectomy cases showed an associated, but slight, increase in the incidence of VTE compared to non-splenectomy cases [121].

Question. What kind of procedure should be

selected when performing a splenectomy?

Answer. Laparoscopic splenectomy is

recommended as it is less invasive, has a

shorter postoperative recovery time and

fewer complications compared to open

splenectomy.

Commentary】 
Previously, open splenectomy (OS) with an incision in the abdominal midline was generally used for splenectomies, but since the 1990s, laparoscopic splenectomies (LS) have become the standard [129]. Winslow et al. conducted a meta-analysis of 2119 LS cases and 821 OS cases [130]. The time required for surgery was significantly longer with LS, but the postoperative hospital stay was significantly shorter with LS (OS 7.2 days vs LS 3.6 days). The incidence of lung and wound complications and infections was also significantly lower with LS. Identification of the accessory spleen was equal in OS and LS. Based on the above findings, LS is recommended, but when bleeding cannot be controlled during LS, it may be necessary to transition to open surgery, so it is preferable to perform splenectomies in institutions with abundant experience in this procedure.
Question. What kind of vaccinations should be used?

Answer. Vaccinate the patient with a 23valent pneumococcal vaccine up to 4 weeks before splenectomy.

\section{Commentary】}

The risk of OPSI increases post-splenectomy and the mortality rate of OPSI can reach $50 \%$. Thus, it is strongly recommended to vaccinate the patient with a 23 -valent vaccine (Pneumovax) to prevent S. pneumoniae infection, which is the most common pneumonia-causative bacteria in Japan $[1,127$, 131]. It is preferable to vaccinate the patient up to 4 weeks before splenectomy to inhibit the onset of perioperative OPSI, but when preoperative vaccination is difficult, the patient should be vaccinated soon after surgery [13]. N. meningitidis and $H$. influenzae can also cause OPSI, but these bacteria are less common in Japan, and neither of the vaccines has been approved. Vaccinations should be considered based on the circumstances of individual patients, such as their intent to travel overseas. 


\section{Third-line treatment}

Conventionally, around 5-30\% of ITP cases do not respond to corticosteroids and splenectomy. Many different types of treatments have been attempted for such "refractory" ITP cases [1, 13]. With the repositioning of TPO-RAs and rituximab to second-line treatment in this revised guide, the number of multi-refractory ITP cases that do not respond to these treatments is expected to be considerably limited, and there are no reports that have summarized how effective drugs used as third-line treatment are in such cases. Therefore, the efficacy of drugs shown in this section is mainly for patients unresponsive to corticosteroids, including patients with initial onset of ITP. Furthermore, these reports are all from small cohorts of patients, and there are no drugs for which large-scale studies or RCTs have been implemented since the previous reference guide, so it is essential to note that the evidence levels of these treatments are low.

These limitations noted, the drugs listed below show potential efficacy for patients with multi-refractory ITP, or patients who have no indication for second-line treatment due to complications or other factors. These drugs may be effective as monotherapies, but they may be more effective if used in combination with other drugs, including TPO-RAs $[132,133]$.

\section{Indication}

Each type of second-line treatment is for patients who did not achieve PR or better, or for patients for whom secondline treatment is contraindicated due to complications or other factors. However, before transitioning to third-line treatment, it is preferable to reconfirm the ITP diagnosis, for example by repeated bone marrow examination. One report has indicated that multi-refractory ITP cases are often secondary ITP with chronic lymphocytic leukemia or SLE [132]. Note that in patients with mild bleeding symptoms, it is preferable to base treatment decisions on the bleeding symptoms, rather than strictly referring to the platelet count, while fully considering the adverse drug reactions associated with each drug.

\section{Drugs with treatment regimen, efficacy and safety}

1. Azathioprine (recommendation level: $2 \mathrm{C}$, not covered by Japanese health insurance). Azathioprine is reported to have a 40-60\% efficacy rate with oral administration of $1-2 \mathrm{mg} / \mathrm{kg} /$ day (maximum dose $150 \mathrm{mg} /$ day) $[134,135]$. Adverse drug reactions include myelosuppression, liver dysfunction, and pancreatitis.
2. Cyclosporine (recommendation level: $2 \mathrm{C}$, not covered by Japanese health insurance). Cyclosporine is reported to have a $30-60 \%$ efficacy rate by maintaining a blood concentration trough level of $100-200 \mathrm{ng} / \mathrm{mL}$ with two doses of $5-6 \mathrm{mg} / \mathrm{kg} /$ day [134]. There are also reports of small-scale studies that achieved a high degree of efficacy with 3-drug combination therapy with azathioprine and mycophenolate mofetil (MMF), or by combining cyclosporine with high-dose dexamethasone and lowdose rituximab [136, 137]. Problematic adverse drug reactions include kidney dysfunction and hypertension.

3. Cyclophosphamide (recommendation level: 2C, not covered by Japanese health insurance). Cyclophosphamide has been reported to have a $24-85 \%$ efficacy rate with $500-1000 \mathrm{mg} / \mathrm{m}^{2}$ intravenous infusion repeated every 3-4 weeks, or $1-2 \mathrm{mg} / \mathrm{kg} /$ day oral administration [134, 138]. Adverse drug reactions include alopecia, myelosuppression, hemorrhagic cystitis, infertility, and secondary primary cancer. It is preferable to avoid administration in young patients who wish to become pregnant.

4. Diaminodiphenyl sulfone (dapsone, 4,4-diaminodiphenylsulphone, DDS. Recommendation level: 2C, not covered by Japanese health insurance). Diaminodiphenyl sulfone is known as a drug used to treat leprosy. The efficacy of this drug in treating ITP has been reported mainly from Europe since the 1990s, but the mechanism of action is unknown. According to a review published in 2013, which summarized eight small-scale prospective and retrospective studies, the efficacy rate is $40-60 \%$ and serious adverse drug reactions are reported to occur in $\leq 15 \%$ patients [139]. However, there are also reports that this drug has a lower efficacy rate (10-20\%) [140, 141]. Known adverse drug reactions include hemolysis (DDS syndrome), hematopoietic disorders, and mucocutaneous disorders.

5. Danazol (recommendation level: 2C, not covered by Japanese health insurance). Reports on the efficacy of the testosterone derivative danazol for treating ITP appeared in the literature for more than 30 years [142]. The normal dose is $200-400 \mathrm{mg} / \mathrm{day}$, but there are also reports of low-dose treatments (50-100 mg/day). Efficacy varies significantly, from 10 to $70 \%$ depending upon the report $[134,143]$. A recently reported meta-analysis, which summarized the results of 12 reports and 224 cases, reported the efficacy as 58\% (95\% CI: $42-72 \%)$, and the complete response rate as $29 \%$ (19-42\%), but many patients were administered $400-800 \mathrm{mg} /$ day [144]. Adverse drug reactions include liver dysfunction, amenorrhea, thrombosis, hoarseness, hirsutism, and androgenization. 
6. Vinca alkaloid (recommendation level: $2 \mathrm{C}$, not covered by Japanese health insurance). The efficacy of vinca alkaloid has been reported since the 1970s. There are various reports on the specific vinca alkaloid used for treatment (vincristine or vinblastine), the administration method (slow venous infusion or bolus), as well as the dose and number of doses. The efficacy varies significantly from 10 to $86 \%$ depending on the report [134, 145]. Normally, this treatment is temporarily effective but does not produce long-term remission. Administration may be considered when attempting to increase the platelet count temporarily in patients non-responsive to IVIG [146]. Adverse drug reactions include constipation and peripheral neuropathy.

7. Mycophenolate mofetil (MMF) (recommendation level: 2C, not covered by Japanese health insurance). Use of MMF for ITP is mainly reported from Europe, and an efficacy rate of $50-60 \%$ has been reported with oral administration of $250-1000 \mathrm{mg} \times 2$ times/day [134, 147-149]. The adverse drug reactions are relatively mild, but gastrointestinal disorders are common.

\section{Treatments in emergencies or surgical procedures}

In patients with life-threatening bleeding associated with profound thrombocytopenia, such as gastrointestinal bleeding or cerebral hemorrhage, and patients who require surgery, it is essential to rapidly increase platelet count to achieve hemostasis. Recommended treatments for such patients are IVIG, methylprednisolone pulse therapy, and platelet transfusion.

\section{Indication}

Emergency treatment is indicated for patients with a platelet count of $\leq 10,000 / \mu \mathrm{L}$ causing bleeding into a major organ (brain, lung, gastrointestinal tract, urinary system, intraabdominal bleeding), or patients at high risk of such an event. Table 3 shows platelet counts necessary for patients who require surgery or invasive treatment.
Table 3 Recommendation for target platelet counts during invasive procedure or surgery $[1,3,13,32,160-163]$

\begin{tabular}{ll}
\hline Procedure/Surgery & $\begin{array}{l}\text { Platelet } \\
\text { count }(\times \\
\left.10^{9} / \mathrm{L}\right)\end{array}$ \\
\hline Dental prophylaxis (descaling, etc.) & $\geq 20-30$ \\
Simple extraction & $\geq 30$ \\
Complex extraction & $\geq 50$ \\
Regional dental block & $\geq 30$ \\
Insertion of central venous catheter & $\geq 20$ \\
Lumber puncture & $\geq 50$ \\
Minor surgery & $\geq 50$ \\
Major surgery & $\geq 80$ \\
Surgery of the central nervous system & $\geq 100$ \\
Splenectomy & $\geq 50$ \\
Delivery & $\geq 50$ \\
Epidural anesthesia & $\geq 80$ \\
\hline
\end{tabular}

\section{High-dose intravenous immunoglobulin (IVIG) (recommendation level: 1B)}

Treatment regimen Administer $400 \mathrm{mg} / \mathrm{kg} / \mathrm{day}$ of human immunoglobulin intravenously for 5 consecutive days. The platelet count starts to increase about 3 days after starting treatment and tends to peak at an average of 7 days after starting treatment. It steadily declines thereafter, with the platelet count remaining higher than the pretreatment level for 2-3 weeks. In Europe and the US, typically $1000 \mathrm{mg} / \mathrm{kg} /$ day is administered for 1-2 days.

Efficacy A report on the effect of IVIG in 282 ITP patients found that $64 \%$ of patients reached a platelet count of $\geq 100,000 / \mu \mathrm{L}$ and $83 \%$ increased their platelet count to $\geq 50,000 / \mu \mathrm{L}$ [150]. A small-scale $(n=27) \mathrm{RCT}$ was conducted that compared the effect of different IVIG doses, $400 \mathrm{mg} / \mathrm{kg} / \mathrm{day} \times 5$ days and $1000 \mathrm{mg} / \mathrm{kg} / \mathrm{day} \times 2$ days, and found that although the latter dose increased the platelet count more rapidly by about 1 day, the duration of platelet count elevation was shorter [151]. There are no reliable indicators for predicting IVIG effect. 
Safety This treatment can cause anaphylactic shock, so the patient should be carefully monitored at the initial administration. It rarely causes acute kidney dysfunction or thromboembolism. Headache is relatively common and tends to occur with rapid infusion. Anti-inflammatory analgesics are effective.

\section{Methylprednisolone pulse therapy (recommendation level: 2B, not covered by Japanese health insurance)}

Treatment regimen Administer 1 g/day methylprednisolone intravenously for 3 consecutive days. The platelet count starts to increase from about day 3, and an increase in the platelet count is seen in approximately $80 \%$ of cases, but in many cases, the increase is temporary, so after pulse therapy, oral prednisolone should be used as maintenance therapy, and the dose tapered thereafter. This treatment can be combined with IVIG and/or platelet transfusion during critical bleeding episodes.
Efficacy A report on using methylprednisolone pulse therapy for 21 patients with a platelet count of $<15,000 / \mu \mathrm{L}$ and mucosal bleeding found that $80 \%$ of patients were responsive, with their platelet count increasing to $\geq 50,000 / \mu \mathrm{L}$, taking an average of 4.7 days to reach that level [152]. A study on 60 patients with a platelet count of $\leq 20,000 / \mu \mathrm{L}$ found that the treatment was effective in $78 \%$ of patients and $60 \%$ of patients reached a platelet count of $\geq 50,000 / \mu \mathrm{L}$ within 4 days [153]. An RCT that compared pulse therapy and IVIG therapy found that IVIG was superior in terms of the time required to increase the platelet count to $50,000 / \mu \mathrm{L}$ and the duration of the effect [153].

Safety Adverse events seen at early stages of treatment include arrhythmia and hyperglycemia, so ECG monitoring is recommended, and blood sugar measurements should be taken, giving note to these issues from the start of administration. Also be aware of other general corticosteroid adverse drug reactions. 
Question. Is methylprednisolone pulse therapy

more effective than conventional oral PSL

therapy in an emergency?

Answer. Methylprednisolone treatment

increases the platelet count more rapidly

than conventional PSL, and the response

rate is also higher, so methylprednisolone

pulse therapy is recommended when urgent

treatment is required.

\section{【ommentary】}

A study (non-RCT) comparing

methylprednisolone pulse therapy (maintained with oral PSL after pulse therapy) and

conventional oral PSL $(1 \mathrm{mg} / \mathrm{kg} /$ day $)$ therapy

found that pulse therapy increased the platelet

count earlier (4.7 days vs 8.7 days, $p<0.0002$ ), and the initial response rate was also better ( $80 \%$ vs $52.7 \%, p<0.05)$. However, the longterm response rate was the same ( $33 \%$ vs $25 \%$, $p=\mathrm{NS})[152,154]$. Pulse therapy was also effective for some patients who were nonresponsive to conventional oral PSL therapy [152]. An RCT was conducted comparing a group administered oral PSL $1 \mathrm{mg} / \mathrm{kg} /$ day for 21 days after methylprednisolone pulse therapy (dose was tapered thereafter) with a group administered a placebo instead of oral PSL, and the study found that the oral PSL treatment group had a significantly better rate of platelet count increase and duration of effect. Therefore, using oral PSL maintenance therapy after pulse therapy appears to be a superior option [153].

\section{Platelet transfusion (recommendation level: 2C)}

Treatment regimen $2 \sim 4 \times 10^{11}$ platelets (10-20 units of platelet concentrates) are administered as a single dose. This treatment has the fastest hemostatic effect, but the presence of anti-platelet antibodies leads to shorter survival of the transfused platelets, and an increase in the platelet count occurs is only temporary. Combining platelet transfusion with IVIG is more effective than either alone, so these treatments are often combined in emergencies.

Efficacy In theory, the platelets transfused into ITP patients are rapidly destroyed by anti-platelet antibodies, so it is not guaranteed that the transfusion can contribute to hemostasis of the bleeding site. However, there are a number of reports of cases in which platelet transfusion alone or in combination with IVIG was clinically effective [155-158].

Safety Take note of adverse reactions associated with transfusion, including fever, urticaria, and anaphylaxis. Platelet transfusion for ITP does not increase the risk of thrombosis [159].

\section{In conclusion}

TPO-RAs and rituximab can now be used for refractory ITP, which makes the selection of treatment methods more difficult. This revision of the Reference Guide for the management of adult ITP contains detailed information particularly on the efficacy and adverse drug reactions/complications associated with second-line treatment for corticosteroid resistance. We endeavored to provide a more detailed explanation on individual matters by adding Q\&A items to 
address clinical questions. We hope this new reference guide will be widely utilized to assist in management of adult ITP patients in the medical setting.

Acknowledgements This reference guide for management of adult ITP was created under the auspices of the Ministry of Health, Labour and Welfare Intractable Disease Policy Research Project, Research Team on Blood Coagulation Abnormalities (Research Representative: Mitsuru Murata). We would like to express our sincere gratitude to all the team members for their valuable input.

\section{Compliance with ethical standards}

Conflict of interest Takaaki Hato: lecture fee (Novartis), Yoshiaki Tomiyama: remuneration (Sysmex Corporation), lecture fee (Novartis, Kyowa Hakko Kirin Co., Ltd., Chugai Pharmaceutical Co., Ltd.).

\section{References}

1. Fujimura K, Miyakawa Y, Kurata Y, Kuwana M, Tomiyama Y, Murata M. Reference guide for management of adult idiopathic thrombocytopenic purpura (ITP) 2012 version. J Jpn Soc Hematol. 2012;53(4):433-42.

2. Neunert C, Lim W, Crowther M, et al. The American Society of Hematology 2011 evidence-based practice guidelines for immune thrombocytopenia. Blood. 2011;117(16):4190-207.

3. Miyakawa Y, Kashiwagi H, Takafuta T, et al. Consensus report for the management of pregnancy with primary immune thrombocytopenia. Rinsho Ketsueki. 2014;55(8):934-47.

4. Cines DB, Blanchette VS. Immune thrombocytopenic purpura. N Engl J Med. 2002;346(13):995-1008.

5. Rodeghiero F, Stasi R, Gernsheimer T, et al. Standardization of terminology, definitions and outcome criteria in immune thrombocytopenic purpura of adults and children: report from an international working group. Blood. 2009;113(11):2386-93.

6. Kurata Y, Fujimura K, Kuwana M, Tomiyama Y, Murata M. Epidemiology of primary immune thrombocytopenia in children and adults in Japan: a population-based study and literature review. Int J Hematol. 2011;93(3):329-35.

7. George JN, el-Harake MA, Raskob GE. Chronic idiopathic thrombocytopenic purpura. N Engl J Med. 1994;331(18):1207-11.

8. Nugent D, McMillan R, Nichol JL, Slichter SJ. Pathogenesis of chronic immune thrombocytopenia: increased platelet destruction and/or decreased platelet production. Br J Haematol. 2009;146(6):585-96.

9. McKenzie CG, Guo L, Freedman J, Semple JW. Cellular immune dysfunction in immune thrombocytopenia (ITP). Br J Haematol. 2013;163(1):10-23.

10. Kashiwagi H, Tomiyama Y. Pathophysiology and management of primary immune thrombocytopenia. Int $\mathrm{J}$ Hematol. 2013;98(1):24-33.

11. Karpatkin S. Autoimmune (idiopathic) thrombocytopenic purpura. Lancet. 1997;349(9064):1531-6.

12. Neunert C, Noroozi N, Norman G, et al. Severe bleeding events in adults and children with primary immune thrombocytopenia: a systematic review. J Thromb Haemost. 2015;13(3):457-64.

13. Provan D, Stasi R, Newland AC, et al. International consensus report on the investigation and management of primary immune thrombocytopenia. Blood. 2010;115(2):168-86.

14. Kurata Y, Hayashi S, Kiyoi T, et al. Diagnostic value of tests for reticulated platelets, plasma glycocalicin, and thrombopoietin levels for discriminating between hyperdestructive and hypoplastic thrombocytopenia. Am J Clin Pathol. 2001;115(5):656-64.

15. Koike Y, Yoneyama A, Shirai J, et al. Evaluation of thrombopoiesis in thrombocytopenic disorders by simultaneous measurement of reticulated platelets of whole blood and serum thrombopoietin concentrations. Thromb Haemost. 1998;79(6):1106-10.

16. Sakuragi M, Hayashi S, Maruyama M, et al. Clinical significance of IPF\% or RP\% measurement in distinguishing primary immune thrombocytopenia from aplastic thrombocytopenic disorders. Int J Hematol. 2015;101(4):369-75.

17. Kuwana M, Kurata Y, Fujimura K, et al. Preliminary laboratory based diagnostic criteria for immune thrombocytopenic purpura: evaluation by multi-center prospective study. J Thromb Haemost. 2006;4(9):1936-43.

18. Kelton JG, Murphy WG, Lucarelli A, et al. A prospective comparison of four techniques for measuring platelet-associated IgG. Br J Haematol. 1989;71(1):97-105.

19. Gasbarrini A, Franceschi F, Tartaglione R, Landolfi R, Pola P, Gasbarrini G. Regression of autoimmune thrombocytopenia after eradication of Helicobacter pylori. Lancet. 1998;352(9131):878.

20. Franchini M, Cruciani M, Mengoli C, Pizzolo G, Veneri D. Effect of Helicobacter pylori eradication on platelet count in idiopathic thrombocytopenic purpura: a systematic review and meta-analysis. J Antimicrob Chemother. 2007;60(2):237-46.

21. Stasi R, Sarpatwari A, Segal JB, et al. Effects of eradication of Helicobacter pylori infection in patients with immune thrombocytopenic purpura: a systematic review. Blood. 2009;113(6):1231-40.

22. Arnold DM, Bernotas A, Nazi I, et al. Platelet count response to $H$. pylori treatment in patients with immune thrombocytopenic purpura with and without $H$. pylori infection: a systematic review. Haematologica. 2009;94(6):850-6.

23. Kikuchi T, Kobayashi T, Yamashita T, Ohashi K, Sakamaki $\mathrm{H}$, Akiyama H. Eight-year follow-up of patients with immune thrombocytopenic purpura related to $H$. pylori infection. Platelets. 2011;22(1):61-4.

24. Asahi A, Kuwana M, Suzuki H, Hibi T, Kawakami Y, Ikeda Y. Effects of a Helicobacter pylori eradication regimen on antiplatelet autoantibody response in infected and uninfected patients with idiopathic thrombocytopenic purpura. Haematologica. 2006;91(10):1436-7.

25. Kuwana M. Helicobacter pylori-associated immune thrombocytopenia: clinical features and pathogenic mechanisms. World J Gastroenterol. 2014;20(3):714-23.

26. The Japanese Society for Helicobacter Research Guideline Preparation Committee. Guideline for the Management of Helicobacter pylori (H. pylori) Infection in Japan 2016 Revision. Sentan Igaku-sha; 2016.

27. Murakami K, Sakurai Y, Shiino M, Funao N, Nishimura A, Asaka M. Vonoprazan, a novel potassium-competitive acid blocker, as a component of first-line and second-line triple therapy for Helicobacter pylori eradication: a phase III, randomised, double-blind study. Gut. 2016;65(9):1439-46.

28. Fujimura K, Kuwana M, Kurata Y, et al. Is eradication therapy useful as the first line of treatment in Helicobacter pylori-positive idiopathic thrombocytopenic purpura? Analysis of 207 eradicated chronic ITP cases in Japan. Int J Hematol. 2005;81(2):162-8.

29. Ito T, Shiromizu T, Ohnishi S, et al. Potential role of extracellular vesicle-mediated antigen presentation in Helicobacter pylori hypersensitivity during eradication therapy. J Allergy Clin Immunol. 2018;142(2):672-6.

30. Kuwana M, Ikeda Y. The role of autoreactive T-cells in the pathogenesis of idiopathic thrombocytopenic purpura. Int J Hematol. 2005;81(2):106-12.

31. McMillan R, Wang L, Tomer A, Nichol J, Pistillo J. Suppression of in vitro megakaryocyte production by antiplatelet 
autoantibodies from adult patients with chronic ITP. Blood. 2004;103(4):1364-9.

32. George JN, Woolf SH, Raskob GE, et al. Idiopathic thrombocytopenic purpura: a practice guidelines developed by explicit methods for the American Society of Hematology. Blood. 1996;88(1):3-40.

33. Force BCfSiHGHT. Guideline for the investigation and management of idiopathic thrombocytopenic purpura in adults, children and in pregnancy. Br J Haematol. 2003;120(4):574-96.

34. Pizzuto J, Ambriz R. Therapeutic experience on 934 adults with idiopathic thrombocytopenic purpura: multicentric trial of the cooperative Latin American group on hemostasis and thrombosis. Blood. 1984;64(6):1179-83.

35. Kusumoto S, Tanaka Y. Reactivation of hepatitis B virus and hepatitis $\mathrm{C}$ virus following immunosuppressive therapy. J Jpn Soc Intern Med. 2014;103(7):1645-53.

36. Andersen JC. Response of resistant idiopathic thrombocytopenic purpura to pulsed high-dose dexamethasone therapy. N Engl J Med. 1994;330(22):1560-4.

37. Arruda VR, Annichino-Bizzacchi JM. High-dose dexamethasone therapy in chronic idiopathic thrombocytopenic purpura. Ann Hematol. 1996;73(4):175-7.

38. Caulier MT, Rose C, Roussel MT, Huart C, Bauters F, Fenaux P. Pulsed high-dose dexamethasone in refractory chronic idiopathic thrombocytopenic purpura: a report on 10 cases. Br J Haematol. 1995;91(2):477-9.

39. Warner M, Wasi P, Couban S, Hayward C, Warkentin T, Kelton JG. Failure of pulse high-dose dexamethasone in chronic idiopathic immune thrombocytopenia. Am J Hematol. 1997;54(4):267-70.

40. Stasi R, Brunetti M, Pagano A, Stipa E, Masi M, Amadori S. Pulsed intravenous high-dose dexamethasone in adults with chronic idiopathic thrombocytopenic purpura. Blood Cells Mol Dis. 2000;26(6):582-6.

41. Borst F, Keuning JJ, van Hulsteijn H, Sinnige H, Vreugdenhil G. High-dose dexamethasone as a first- and second-line treatment of idiopathic thrombocytopenic purpura in adults. Ann Hematol. 2004;83(12):764-8.

42. Naithani R, Mahapatra M, Kumar R, Mishra P, Saxena R. High dose dexamethasone therapy shows better responses in acute immune thrombocytopenia than in chronic immune thrombocytopenia. Platelets. 2010;21(4):270-3.

43. Nakazaki K, Hosoi M, Hangaishi A, Ichikawa M, Nannya Y, Kurokawa M. Comparison between pulsed high-dose dexamethasone and daily corticosteroid therapy for adult primary immune thrombocytopenia: a retrospective study. Intern Med. 2012;51(8):859-63.

44. Sakamoto K, Nakasone H, Tsurumi S, et al. Prednisone versus high-dose dexamethasone for untreated primary immune thrombocytopenia. A retrospective study of the Japan Hematology \& Oncology Clinical Study Group. J Thromb Thrombolysis. 2014;37(3):279-86.

45. Cheng Y, Wong RS, Soo YO, et al. Initial treatment of immune thrombocytopenic purpura with high-dose dexamethasone. N Engl J Med. 2003;349(9):831-6.

46. Mazzucconi MG, Fazi P, Bernasconi S, et al. Therapy with highdose dexamethasone (HD-DXM) in previously untreated patients affected by idiopathic thrombocytopenic purpura: a GIMEMA experience. Blood. 2007;109(4):1401-7.

47. Din B, Wang X, Shi Y, Li Y. Long-term effect of high-dose dexamethasone with or without low-dose dexamethasone maintenance in untreated immune thrombocytopenia. Acta Haematol. 2015;133(1):124-8.

48. Praituan W, Rojnuckarin P. Faster platelet recovery by high-dose dexamethasone compared with standard-dose prednisolone in adult immune thrombocytopenia: a prospective randomized trial. J Thromb Haemost. 2009;7(6):1036-8.

49. Matschke J, Muller-Beissenhirtz H, Novotny J, et al. A randomized trial of daily prednisone versus pulsed dexamethasone in treatment-naive adult patients with immune thrombocytopenia: EIS 2002 Study. Acta Haematol. 2016;136(2):101-7.

50. Wei Y, Ji XB, Wang YW, et al. High-dose dexamethasone vs prednisone for treatment of adult immune thrombocytopenia: a prospective multicenter randomized trial. Blood. 2016;127(3):296-302.

51. Mithoowani S, Gregory-Miller K, Goy J, et al. High-dose dexamethasone compared with prednisone for previously untreated primary immune thrombocytopenia: a systematic review and meta-analysis. Lancet Haematol. 2016;3(10):e489-96.

52. Rodeghiero F, Stasi R, Giagounidis A, et al. Long-term safety and tolerability of romiplostim in patients with primary immune thrombocytopenia: a pooled analysis of 13 clinical trials. Eur J Haematol. 2013;91(5):423-36.

53. Wong RSM, Saleh MN, Khelif A, et al. Safety and efficacy of long-term treatment of chronic/persistent ITP with eltrombopag: final results of the EXTEND study. Blood. 2017;130(23):2527-36.

54. Bussel JB, Kuter DJ, George JN, et al. AMG 531, a thrombopoiesis-stimulating protein, for chronic ITP. N Engl J Med. 2006;355(16):1672-81.

55. Kuter DJ, Bussel JB, Lyons RM, et al. Efficacy of romiplostim in patients with chronic immune thrombocytopenic purpura: a double-blind randomised controlled trial. Lancet. 2008;371(9610):395-403.

56. Kuter DJ, Rummel M, Boccia R, et al. Romiplostim or standard of care in patients with immune thrombocytopenia. N Engl J Med. 2010;363(20):1889-99.

57. Shirasugi Y, Ando K, Miyazaki K, et al. Romiplostim for the treatment of chronic immune thrombocytopenia in adult Japanese patients: a double-blind, randomized Phase III clinical trial. Int J Hematol. 2011;94(1):71-80.

58. Bussel JB, Buchanan GR, Nugent DJ, et al. A randomized, double-blind study of romiplostim to determine its safety and efficacy in children with immune thrombocytopenia. Blood. 2011;118(1):28-36.

59. Bussel JB, Cheng G, Saleh MN, et al. Eltrombopag for the treatment of chronic idiopathic thrombocytopenic purpura. N Engl J Med. 2007;357(22):2237-47.

60. Bussel JB, Provan D, Shamsi T, et al. Effect of eltrombopag on platelet counts and bleeding during treatment of chronic idiopathic thrombocytopenic purpura: a randomised, double-blind, placebo-controlled trial. Lancet. 2009;373(9664):641-8.

61. Cheng G, Saleh MN, Marcher C, et al. Eltrombopag for management of chronic immune thrombocytopenia (RAISE): a 6-month, randomised, phase 3 study. Lancet. 2011;377(9763):393-402.

62. Tomiyama Y, Miyakawa Y, Okamoto S, et al. A lower starting dose of eltrombopag is efficacious in Japanese patients with previously treated chronic immune thrombocytopenia. J Thromb Haemost. 2012;10(5):799-806.

63. Kuter DJ, Bussel JB, Newland A, et al. Long-term treatment with romiplostim in patients with chronic immune thrombocytopenia: safety and efficacy. Br J Haematol. 2013;161(3):411-23.

64. Wang L, Gao Z, Chen XP, et al. Efficacy and safety of thrombopoietin receptor agonists in patients with primary immune thrombocytopenia: a systematic review and meta-analysis. Sci Rep. 2016;6:39003.

65. Elgebaly AS, Ashal GE, Elfil M, Menshawy A. Tolerability and efficacy of eltrombopag in chronic immune thrombocytopenia: meta-analysis of randomized controlled trials. Clin Appl Thromb Hemost. 2017;23(8):928-37. 
66. Cines DB, Wasser J, Rodeghiero F, et al. Safety and efficacy of romiplostim in splenectomized and nonsplenectomized patients with primary immune thrombocytopenia. Haematologica. 2017;102(8):1342-51.

67. Steurer M, Quittet P, Papadaki HA, et al. A large observational study of patients with primary immune thrombocytopenia receiving romiplostim in European clinical practice. Eur J Haematol. 2017;98(2):112-20.

68. Gonzalez-Lopez TJ, Alvarez-Roman MT, Pascual C, et al. Eltrombopag safety and efficacy for primary chronic immune thrombocytopenia in clinical practice. Eur J Haematol. 2016;97(3):297-302.

69. Ghadaki B, Nazi I, Kelton JG, Arnold DM. Sustained remissions of immune thrombocytopenia associated with the use of thrombopoietin receptor agonists. Transfusion. 2013;53(11):2807-12.

70. Mahevas M, Fain O, Ebbo M, et al. The temporary use of thrombopoietin-receptor agonists may induce a prolonged remission in adult chronic immune thrombocytopenia. Results of a French observational study. Br J Haematol. 2014;165(6):865-9.

71. Cervinek L, Mayer J, Doubek M. Sustained remission of chronic immune thrombocytopenia after discontinuation of treatment with thrombopoietin-receptor agonists in adults. Int J Hematol. 2015;102(1):7-11.

72. Gonzalez-Lopez TJ, Pascual C, Alvarez-Roman MT, et al. Successful discontinuation of eltrombopag after complete remission in patients with primary immune thrombocytopenia. Am J Hematol. 2015;90(3):E40-3.

73. Bao W, Bussel JB, Heck S, et al. Improved regulatory T-cell activity in patients with chronic immune thrombocytopenia treated with thrombopoietic agents. Blood. 2010;116(22):4639-45.

74. Nishimoto T, Numajiri M, Nakazaki H, Okazaki Y, Kuwana M. Induction of immune tolerance to platelet antigen by short-term thrombopoietin treatment in a mouse model of immune thrombocytopenia. Int J Hematol. 2014;100(4):341-4.

75. Oda A, Miyakawa Y, Druker BJ, et al. Thrombopoietin-induced signal transduction and potentiation of platelet activation. Thromb Haemost. 1999;82(2):377-84.

76. Sarpatwari A, Bennett D, Logie JW, et al. Thromboembolic events among adult patients with primary immune thrombocytopenia in the United Kingdom General Practice Research Database. Haematologica. 2010;95(7):1167-75.

77. Nørgaard M, Severinsen MT, Lund Maegbaek M, Jensen A, Cha S, Sørensen HT. Risk of arterial thrombosis in patients with primary chronic immune thrombocytopenia: a Danish populationbased cohort study. Br J Haematol. 2012;159(1):109-11.

78. Severinsen MT, Engebjerg MC, Farkas DK, et al. Risk of venous thromboembolism in patients with primary chronic immune thrombocytopenia: a Danish population-based cohort study. $\mathrm{Br}$ J Haematol. 2011;152(3):360-2.

79. Saleh MN, Bussel JB, Cheng G, et al. Safety and efficacy of eltrombopag for treatment of chronic immune thrombocytopenia: results of the long-term, open-label EXTEND study. Blood. 2013;121(3):537-45.

80. Brynes RK, Orazi A, Theodore D, et al. Evaluation of bone marrow reticulin in patients with chronic immune thrombocytopenia treated with eltrombopag: data from the EXTEND study. Am J Hematol. 2015;90(7):598-601.

81. Ghanima W, Geyer JT, Lee CS, et al. Bone marrow fibrosis in 66 patients with immune thrombocytopenia treated with thrombopoietin-receptor agonists: a single-center, long-term follow-up. Haematologica. 2014;99(5):937-44.

82. Kantarjian H, Fenaux P, Sekeres MA, et al. Safety and efficacy of romiplostim in patients with lower-risk myelodysplastic syndrome and thrombocytopenia. J Clin Oncol. 2010;28(3):437-44.

83. Kantarjian HM, Fenaux P, Sekeres MA, et al. Long-term follow-up for up to 5 years on the risk of leukaemic progression in thrombocytopenic patients with lower-risk myelodysplastic syndromes treated with romiplostim or placebo in a randomised double-blind trial. Lancet Haematol. 2018;5(3):e117-26.

84. Oshima Y, Yuji K, Tanimoto T, Hinomura Y, Tojo A. Association between acute myelogenous leukemia and thrombopoietin receptor agonists in patients with immune thrombocytopenia. Intern Med. 2013;52(19):2193-201.

85. Cuker A. Toxicities of the thrombopoietic growth factors. Semin Hematol. 2010;47(3):289-98.

86. Zhang J, Liang Y, Ai Y, et al. Eltrombopag versus romiplostim in treatment of adult patients with immune thrombocytopenia: a systematic review incorporating an indirect-comparison metaanalysis. PLoS One. 2018;13(6): 0198504.

87. Khellaf M, Viallard JF, Hamidou M, et al. A retrospective pilot evaluation of switching thrombopoietic receptor-agonists in immune thrombocytopenia. Haematologica. 2013;98(6):881-7.

88. Gonzalez-Porras JR, Mingot-Castellano ME, Andrade MM, et al. Use of eltrombopag after romiplostim in primary immune thrombocytopenia. Br J Haematol. 2015;169(1):111-6.

89. Lakhwani S, Perera M, Fernandez-Fuertes F, et al. Thrombopoietin receptor agonist switch in adult primary immune thrombocytopenia patients: a retrospective collaborative survey involving 4 Spanish centres. Eur J Haematol. 2017;99(4):372-7.

90. Cantoni S, Carpenedo M, Mazzucconi MG, et al. Alternate use of thrombopoietin receptor agonists in adult primary immune thrombocytopenia patients: a retrospective collaborative survey from Italian hematology centers. Am J Hematol. 2018;93(1):58-64.

91. Chugh S, Darvish-Kazem S, Lim W, et al. Rituximab plus standard of care for treatment of primary immune thrombocytopenia: a systematic review and meta-analysis. Lancet Haematol. 2015;2(2):e75-81.

92. Gudbrandsdottir S, Birgens HS, Frederiksen H, et al. Rituximab and dexamethasone vs dexamethasone monotherapy in newly diagnosed patients with primary immune thrombocytopenia. Blood. 2013;121(11):1976-81.

93. Zaja F, Baccarani M, Mazza P, et al. Dexamethasone plus rituximab yields higher sustained response rates than dexamethasone monotherapy in adults with primary immune thrombocytopenia. Blood. 2010;115(14):2755-62.

94. Arnold DM, Heddle NM, Carruthers J, et al. A pilot randomized trial of adjuvant rituximab or placebo for nonsplenectomized patients with immune thrombocytopenia. Blood. 2012;119(6):1356-62.

95. Li Z, Mou W, Lu G, et al. Low-dose rituximab combined with short-term glucocorticoids up-regulates Treg cell levels in patients with immune thrombocytopenia. Int $\mathbf{J}$ Hematol. 2011;93(1):91-8.

96. Ghanima W, Khelif A, Waage A, et al. Rituximab as second-line treatment for adult immune thrombocytopenia (the RITP trial): a multicentre, randomised, double-blind, placebo-controlled trial. Lancet. 2015;385(9978):1653-61.

97. Miyakawa Y, Katsutani S, Yano T, et al. Efficacy and safety of rituximab in Japanese patients with relapsed chronic immune thrombocytopenia refractory to conventional therapy. Int J Hematol. 2015;102(6):654-61.

98. Garcia-Chavez J, Majluf-Cruz A, Montiel-Cervantes L, Esparza MG, Vela-Ojeda J, Mexican Hematology Study G. Rituximab therapy for chronic and refractory immune thrombocytopenic purpura: a long-term follow-up analysis. Ann Hematol. 2007;86(12):871-7.

99. Godeau B, Porcher R, Fain O, et al. Rituximab efficacy and safety in adult splenectomy candidates with chronic immune thrombocytopenic purpura: results of a prospective multicenter phase 2 study. Blood. 2008;112(4):999-1004. 
100. Zwaginga JJ, van der Holt B, Te Boekhorst PA, et al. Multi-center randomized open label phase II trial on three rituximab dosing schemes in immune thrombocytopenia patients. Haematologica. 2015;100(3):e90-2.

101. Patel VL, Mahevas M, Lee SY, et al. Outcomes 5 years after response to rituximab therapy in children and adults with immune thrombocytopenia. Blood. 2012;119(25):5989-95.

102. Marangon M, Vianelli N, Palandri F, et al. Rituximab in immune thrombocytopenia: gender, age, and response as predictors of long-term response. Eur J Haematol. 2017;98(4):371-7.

103. Auger S, Duny Y, Rossi JF, Quittet P. Rituximab before splenectomy in adults with primary idiopathic thrombocytopenic purpura: a meta-analysis. Br J Haematol. 2012;158(3):386-98.

104. Hasan A, Michel M, Patel V, et al. Repeated courses of rituximab in chronic ITP: Three different regimens. Am J Hematol. 2009;84(10):661-5.

105. Khellaf M, Charles-Nelson A, Fain O, et al. Safety and efficacy of rituximab in adult immune thrombocytopenia: results from a prospective registry including 248 patients. Blood. 2014;124(22):3228-36.

106. Chapin J, Lee CS, Zhang H, Zehnder JL, Bussel JB. Gender and duration of disease differentiate responses to rituximab-dexamethasone therapy in adults with immune thrombocytopenia. Am J Hematol. 2016;91(9):907-11.

107. Cooper N, Stasi R, Cunningham-Rundles S, et al. The efficacy and safety of B-cell depletion with anti-CD20 monoclonal antibody in adults with chronic immune thrombocytopenic purpura. Br J Haematol. 2004;125(2):232-9.

108. Arnold DM, Vrbensky JR, Karim N, et al. The effect of rituximab on anti-platelet autoantibody levels in patients with immune thrombocytopenia. Br J Haematol. 2017;178(2):302-7.

109. Porcelijn L, Huiskes E, Schipperus M, et al. Lack of detectable platelet autoantibodies is correlated with nonresponsiveness to rituximab treatment in ITP patients. Blood. 2017;129(25):3389-91.

110. Feng R, Liu X, Zhao Y, et al. GPIIb/IIIa autoantibody predicts better rituximab response in ITP. Br J Haematol. 2018;182(2):305-7.

111. Dierickx D, Verhoef G, Van Hoof A, et al. Rituximab in autoimmune haemolytic anaemia and immune thrombocytopenic purpura: a Belgian retrospective multicentric study. J Intern Med. 2009;266(5):484-91.

112. Carson KR, Evens AM, Richey EA, et al. Progressive multifocal leukoencephalopathy after rituximab therapy in HIV-negative patients: a report of 57 cases from the Research on Adverse Drug Events and Reports project. Blood. 2009;113(20):4834-40.

113. Venna N, Gonzalez RG, Camelo-Piragua SI. Case records of the Massachusetts General Hospital. Case 11-2010. A 69-yearold woman with lethargy, confusion, and abnormalities on brain imaging. N Engl J Med. 2010;362(15):1431-7.

114. Provan D, Butler T, Evangelista ML, Amadori S, Newland AC, Stasi R. Activity and safety profile of low-dose rituximab for the treatment of autoimmune cytopenias in adults. Haematologica. 2007;92(12):1695-8.

115. Zaja F, Vianelli N, Volpetti S, et al. Low-dose rituximab in adult patients with primary immune thrombocytopenia. Eur J Haematol. 2010;85(4):329-34.

116. Zaja F, Volpetti S, Chiozzotto M, et al. Long-term follow-up analysis after rituximab salvage therapy in adult patients with immune thrombocytopenia. Am J Hematol. 2012;87(9):886-9.

117. Tran H, Brighton T, Grigg A, et al. A multi-centre, single-arm, open-label study evaluating the safety and efficacy of fixed dose rituximab in patients with refractory, relapsed or chronic idiopathic thrombocytopenic purpura (R-ITP1000 study). Br J Haematol. 2014;167(2):243-51.
118. Kuwana M, Okazaki Y, Ikeda Y. Splenic macrophages maintain the anti-platelet autoimmune response via uptake of opsonized platelets in patients with immune thrombocytopenic purpura. J Thromb Haemost. 2009;7(2):322-9.

119. Stasi R. Immune thrombocytopenia: pathophysiologic and clinical update. Semin Thromb Hemost. 2012;38(5):454-62.

120. Borges da Silva H, Fonseca R, Pereira RM, Cassado Ados A, Alvarez JM, D'Imperio Lima MR. Splenic macrophage subsets and their function during blood-borne infections. Front Immunol. 2015;6:480.

121. Chaturvedi S, Arnold DM, McCrae KR. Splenectomy for immune thrombocytopenia: down but not out. Blood. 2018;131(11):1172-82.

122. Gonzalez-Porras JR, Escalante F, Pardal E, et al. Safety and efficacy of splenectomy in over 65-years-old patients with immune thrombocytopenia. Eur J Haematol. 2013;91(3):236-41.

123. Zaja F, Barcellini W, Cantoni S, et al. Thrombopoietin receptor agonists for preparing adult patients with immune thrombocytopenia to splenectomy: results of a retrospective, observational GIMEMA study. Am J Hematol. 2016;91(5):E293-5.

124. Kojouri K, Vesely SK, Terrell DR, George JN. Splenectomy for adult patients with idiopathic thrombocytopenic purpura: a systematic review to assess long-term platelet count responses, prediction of response, and surgical complications. Blood. 2004;104(9):2623-34.

125. Kuramoto A, Oda K, Kawano H, et al. Multi-center study on long-term follow-up results of splenectomy Research team on Ministry of Health and Welfare designated ideopathic hematopoietic disorders (Team leader: Takao Murano). 1992 Res Rep. 1993;3:130-3.

126. Weledji EP. Benefits and risks of splenectomy. Int J Surg. 2014;12(2):113-9.

127. Sinwar PD. Overwhelming post splenectomy infection syndrome-review study. Int J Surg. 2014;12(12):1314-6.

128. Boyle S, White RH, Brunson A, Wun T. Splenectomy and the incidence of venous thromboembolism and sepsis in patients with immune thrombocytopenia. Blood. 2013;121(23):4782-90.

129. Dolan JP, Sheppard BC, DeLoughery TG. Splenectomy for immune thrombocytopenic purpura: surgery for the 21 st century. Am J Hematol. 2008;83(2):93-6.

130. Winslow ER, Brunt LM. Perioperative outcomes of laparoscopic versus open splenectomy: a meta-analysis with an emphasis on complications. Surgery. 2003;134(4):647-53.

131. Rubin LG, Schaffner W. Clinical practice. Care of the asplenic patient. N Engl J Med. 2014;371(4):349-56.

132. Mahevas M, Gerfaud-Valentin M, Moulis G, et al. Characteristics, outcome, and response to therapy of multirefractory chronic immune thrombocytopenia. Blood. 2016;128(12):1625-30.

133. Boruchov DM, Gururangan S, Driscoll MC, Bussel JB. Multiagent induction and maintenance therapy for patients with refractory immune thrombocytopenic purpura (ITP). Blood. 2007;110(10):3526-31.

134. Cuker A, Neunert CE. How I treat refractory immune thrombocytopenia. Blood. 2016;128(12):1547-54.

135. Chang H, Tang TC, Hung YS, et al. Immune thrombocytopenia: Effectiveness of frontline steroids and comparison of azathioprine, splenectomy, and rituximab as second-line treatment. Eur J Haematol. 2018;101(4):549-55.

136. Arnold DM, Nazi I, Santos A, et al. Combination immunosuppressant therapy for patients with chronic refractory immune thrombocytopenic purpura. Blood. 2010;115(1):29-31.

137. Choi PY, Roncolato F, Badoux X, Ramanathan S, Ho SJ, Chong BH. A novel triple therapy for ITP using high-dose dexamethasone, low-dose rituximab, and cyclosporine (TT4). Blood. 2015;126(4):500-3. 
138. Reiner A, Gernsheimer T, Slichter SJ. Pulse cyclophosphamide therapy for refractory autoimmune thrombocytopenic purpura. Blood. 1995;85(2):351-8.

139. Rodrigo C, Gooneratne L. Dapsone for primary immune thrombocytopenia in adults and children: an evidence-based review. $\mathrm{J}$ Thromb Haemost. 2013;11(11):1946-53.

140. Lee JY, Lee JO, Jung JY, Bang SM. Dapsone therapy for refractory immune thrombocytopenia patients: a case series. Blood Res. 2017;52(2):95-9.

141. Oo T, Hill QA. Disappointing response to dapsone as second line therapy for primary ITP: a case series. Ann Hematol. 2015;94(6):1053-4.

142. Ahn Y, Harrington W, Simon S, Mylvaganam R, Pall L, So A. Danazol for the treatment of idiopathic thrombocytopenic purpura. N Engl J Med. 1983;308(23):1396-9.

143. Liu W, Gu X, Fu R, et al. The effect of danazol in primary immune thrombocytopenia: an analysis of a large cohort from a single center in China. Clin Appl Thromb Hemost. 2016;22(8):727-33.

144. Weber E, Reynaud Q, Fort R, et al. Immunomodulatory treatments for persistent and chronic immune thrombocytopenic purpura: a PRISMA-compliant systematic review and meta-analysis of 28 studies. Medicine (Baltimore). 2017;96(37):e7534.

145. Stirnemann J, Kaddouri N, Khellaf M, et al. Vincristine efficacy and safety in treating immune thrombocytopenia: a retrospective study of 35 patients. Eur J Haematol. 2016;96(3):269-75.

146. Audia S, Godeau B, Bonnotte B. Is there still a place for "old therapies" in the management of immune thrombocytopenia? Rev Med Intern. 2016;37(1):43-9.

147. Taylor A, Neave L, Solanki S, et al. Mycophenolate mofetil therapy for severe immune thrombocytopenia. Br J Haematol. 2015;171(4):625-30.

148. Colovic M, Suvajdzic N, Colovic N, Tomin D, Vidovic A, Palibrk V. Mycophenolate mophetil therapy for chronic immune thrombocytopenic purpura resistant to steroids, immunosuppressants, and/or splenectomy in adults. Platelets. 2011;22(2):153-6.

149. Provan D, Moss AJ, Newland AC, Bussel JB. Efficacy of mycophenolate mofetil as single-agent therapy for refractory immune thrombocytopenic purpura. Am J Hematol. 2006;81(1):19-25.

150. Bussel JB, Pham LC. Intravenous treatment with gammaglobulin in adults with immune thrombocytopenic purpura: review of the literature. Vox Sang. 1987;52(3):206-11.

151. Kurlander R, Coleman RE, Moore J, Gockerman J, Rosse W, Siegal R. Comparison of the efficacy of a two-day and a five-day schedule for infusing intravenous gamma globulin in the treatment of immune thrombocytopenic purpura in adults. Am J Med. 1987;83(4A):17-24.

152. Alpdogan O, Budak-Alpdogan T, Ratip S, et al. Efficacy of highdose methylprednisolone as a first-line therapy in adult patients with idiopathic thrombocytopenic purpura. Br J Haematol. 1998;103(4):1061-3.

153. Godeau B, Chevret S, Varet B, et al. Intravenous immunoglobulin or high-dose methylprednisolone, with or without oral prednisone, for adults with untreated severe autoimmune thrombocytopenic purpura: a randomised, multicentre trial. Lancet. 2002;359(9300):23-9.

154. von dem Borne AE, Vos JJ, Pegels JG, Thomas LL, van der L. High dose intravenous methylprednisolone or high dose intravenous gammaglobulin for autoimmune thrombocytopenia. Br Med J (Clin Res Ed). 1988;296(6617):249-50.

155. Carr JM, Kruskall MS, Kaye JA, Robinson SH. Efficacy of platelet transfusions in immune thrombocytopenia. Am J Med. 1986;80(6):1051-4.

156. Salama A, Kiesewetter H, Kalus U, Movassaghi K, Meyer O. Massive platelet transfusion is a rapidly effective emergency treatment in patients with refractory autoimmune thrombocytopenia. Thromb Haemost. 2008;100(5):762-5.

157. Spahr JE, Rodgers GM. Treatment of immune-mediated thrombocytopenia purpura with concurrent intravenous immunoglobulin and platelet transfusion: a retrospective review of 40 patients. Am J Hematol. 2008;83(2):122-5.

158. Danese MD, Lindquist K, Gleeson M, Deuson R, Mikhael J. Cost and mortality associated with hospitalizations in patients with immune thrombocytopenic purpura. Am J Hematol. 2009;84(10):631-5.

159. Goel R, Ness PM, Takemoto CM, Krishnamurti L, King KE, Tobian AA. Platelet transfusions in platelet consumptive disorders are associated with arterial thrombosis and in-hospital mortality. Blood. 2015;125(9):1470-6.

160. British Committee for Standards in Haematology General Haematology Task Force. Guideline for the investigation and management of idiopathic thrombocytopenic purpura in adults, children and in pregnancy. Br J Haematol. 2003;120(4):574-96.

161. Zeidler K, Arn K, Senn O, Schanz U, Stussi G. Optimal preprocedural platelet transfusion threshold for central venous catheter insertions in patients with thrombocytopenia. Transfusion. 2011;51(11):2269-76.

162. Bishop JF, Schiffer CA, Aisner J, Matthews JP, Wiernik PH. Surgery in acute leukemia: a review of 167 operations in thrombocytopenic patients. Am J Hematol. 1987;26(2):147-55.

163. Goodier CG, Lu JT, Hebbar L, Segal BS, Goetzl L. Neuraxial anesthesia in parturients with thrombocytopenia: a multisite retrospective cohort study. Anesth Analg. 2015;121(4):988-91.

Publisher's Note Springer Nature remains neutral with regard to jurisdictional claims in published maps and institutional affiliations. 